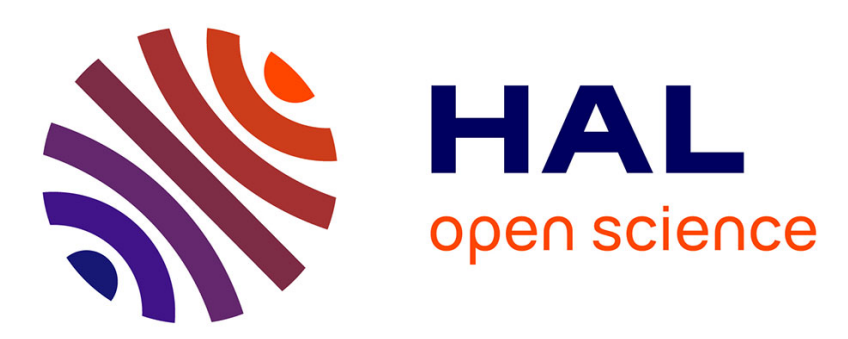

\title{
Simultaneous monitoring of acidity and intercalation for layered transition metal oxides in liquid media
}

\author{
Ghinwa Fayad, Philippe Boullay, Guillaume Clet
}

\section{To cite this version:}

Ghinwa Fayad, Philippe Boullay, Guillaume Clet. Simultaneous monitoring of acidity and intercalation for layered transition metal oxides in liquid media. Journal of Colloid and Interface Science, 2020, 570, pp.41-51. 10.1016/j.jcis.2020.02.088 . hal-02492300

HAL Id: hal-02492300

https://hal-normandie-univ.archives-ouvertes.fr/hal-02492300

Submitted on 29 Sep 2021

HAL is a multi-disciplinary open access archive for the deposit and dissemination of scientific research documents, whether they are published or not. The documents may come from teaching and research institutions in France or abroad, or from public or private research centers.
L'archive ouverte pluridisciplinaire HAL, est destinée au dépôt et à la diffusion de documents scientifiques de niveau recherche, publiés ou non, émanant des établissements d'enseignement et de recherche français ou étrangers, des laboratoires publics ou privés. 


\title{
Simultaneous monitoring of acidity and intercalation for layered transition metal oxides in liquid media.
}

\author{
Ghinwa Fayad, ${ }^{\mathrm{a}}$ Philippe Boullay, ${ }^{\mathrm{b}}$ Guillaume Clet $^{\mathrm{a}, *}$ \\ ${ }^{a}$ Normandie Univ, ENSICAEN, UNICAEN, CNRS, LCS, 14000 Caen, France \\ ${ }^{\mathrm{b}}$ Normandie Univ, ENSICAEN, UNICAEN, CNRS, CRISMAT, 14000 Caen, France
}

Keywords: Layered materials ; Liquid phase ; Intercalation ; Acidity ; Raman spectroscopy ; $\mathrm{HNbMoO}_{6} ; \mathrm{HNbWO}_{6} ; \mathrm{H}_{2} \mathrm{~W}_{2} \mathrm{O}_{7} ; \mathrm{H}_{2} \mathrm{WO}_{4} ;$ Pyridine ; Alkylamine.

\begin{abstract}
Layered transition metal oxides have a potential as catalysts for biomass conversions or as adsorbents. A better understanding of their properties is thus necessary, notably in liquid phase, where these materials have the specificity to intercalate molecules within their interlayers. To discriminate between potential catalysts or adsorbents, it is desirable to study the surface properties in the conditions of intercalation. The intercalation behaviour and acidity of four different acidic layered materials: pure tungstate phases $\mathrm{H}_{2} \mathrm{~W}_{2} \mathrm{O}_{7}, \mathrm{H}_{2} \mathrm{WO}_{4}$ and mixed oxides $\mathrm{HNbWO}_{6}$ and $\mathrm{HNbMoO}_{6}$ have thus been investigated directly in liquid phase. Besides Powder Xray diffraction, Raman spectroscopy provided valuable informations first during the preliminary protonation step and second by monitoring both the intercalation of liquid organic bases and the accessible acidity. N-alkylamines such as butylamine and octylamine were found unsuitable to discriminate the layered solids while pyridine was more selective. Pyridine did not intercalate in $\mathrm{H}_{2} \mathrm{~W}_{2} \mathrm{O}_{7}$, highlighting also the lower acidity of this solid, but gave rise to new Raman features for $\mathrm{H}_{2} \mathrm{WO}_{4}, \mathrm{HNbMoO}_{6}$ and $\mathrm{HNbWO}_{6}$. Lewis and Brønsted acid sites could be discriminated from the perturbation of the inorganic layers and related to surface sites. Therefore, the characterization by Raman spectroscopy in conditions of liquid intercalation proves to efficiently evaluate layered materials.
\end{abstract}




\section{Introduction}

The use of environmentally friendly renewable sources for energy or chemicals induces various modifications of the processing conditions compared to petroleum-based resources. The characteristics of these new resources, such as biomass, and the conditions commonly used for their production often imply reactions in the liquid phase, notably in presence of water [1,2]. This requires the adaptation of the catalysts used in these processes either by modifying existing catalysts or developing new ones. Similar concerns can be found for adsorbents in liquids. Another consequence of these changes concerns the characterization of the catalysts. While characterizations of solids are widely developed in the presence of gaseous molecules (adsorbates, reactants ...), the characterizations of solid catalysts in liquid media are not so numerous. Consequently characterization methods should be improved to support the development of catalysts suitable for biomass conversions.

Several types of solid acid catalysts, such as zeolites, or supported oxides may be considered for biomass conversion [3,4]. However, some of these catalysts suffer from their use in liquid media and/or the presence of water, due to active phase leaching or acid sites poisoning $[5,6]$. The development of stable solid acid catalysts in aqueous media remains a major challenge [7]. Possible candidates might be found among layered transition metal oxides (also in the form of exfoliated nanosheets). These materials may be used for electronic applications or photocatalysis $[8,9]$ but they have also been shown to be promising candidates for catalysis, notably biomass conversions [10-12]. Compared to supported transition metal oxides, they possess sites of comparable acidity, but as bulk materials they have the advantage of higher stability in liquids or in presence of water [13]. A specificity of these materials is their capability to intercalate molecules in their interlayers $[13,14]$ as illustrated extensively by Domen and co-workers who studied several catalytic reactions such as saccharides hydrolysis into glucose $[13,15]$, FriedelCrafts alkylation of anisole, toluene or benzene [10,16], esterification of acetic acid and acetalization of cyclohexanone [17] over several layered transition metal oxides compared to ionexchange resins and zeolites. Layered transition metal oxides including $\mathrm{HTiNbO}_{5}, \mathrm{HNbWO}_{6}$, $\mathrm{HTaWO}_{6}$ and $\mathrm{HNb}_{3} \mathrm{O}_{8}$ were used in the dehydration of xylose into furfural [12] and fructose into 5-hydroxymethylfurfural [11]. Layered $\mathrm{HNbMoO}_{6}$ exhibit remarkable catalytic activity for the hydrolysis of saccharides such as sucrose, starch and cellobiose into glucose, for Friedel-Crafts alkylation of benzyl alcohol and esterification of hydrocarboxylic acids as demonstrated by Domen and coll. [14-16]. This was attributed to the facile intercalation of reactants within the interlayer gallery. Therefore, this step is the key requirement for their catalytic activity as it grants 
access to the acidic sites which are located in the interlayer [15,18-20]. However, intercalation occurs in the liquid phase, which implies that these materials should ideally be characterized in the liquid phase. At present intercalation in layered materials is mostly studied by powder X-ray diffraction of the dried material [21-23] but rarely directly in the liquid phase. The above cited layered materials have generally been examined by $\mathrm{NH}_{3}$ TPD [11,16,24-26] but these gas phase results raise questions on the actual accessibility of the acidic sites in the liquid phase. Interesting results were obtained by Domen and coll. [16,24,25] by liquid phase adsorption of trimethylphosphine oxide as a probe molecule followed by NMR. Nevertheless, these experiments appear rather cumbersome to carry out as they must be done in air-free conditions. Although strong acid sites could be analysed on $\mathrm{HNbMoO}_{6}$, measurements on structurally related $\mathrm{HNbWO}_{6}$ or $\mathrm{HTaWO}_{6}$ were unsuccessful while their exfoliated nanosheets could be analysed. This was attributed to the lack of intercalation of the probe and points out the importance of the size of the probe to enable intercalation. Therefore, alternative characterization methods of the acidity of layered materials in the liquid phase would be interesting to fully evaluate layered solids, especially if this can be conducted in parallel to the monitoring of intercalation and the evolution of the solid. This article intends to fill the gap between the various characterization approaches by probing simultaneously the intercalation process and the acidity of layered materials directly in liquid media. This is necessary to select rationally these materials as catalysts or adsorbents by specifically comparing their ability to intercalate various molecules, their acidity and the role of the metal oxides.

Interestingly, layered materials are often tested for their ability to intercalate amines, and several studies have shown that the extent of intercalation was directly related to the amine chain length $[22,23]$. N-alkylamines are often used in structural studies of layered materials, but their strong basicity and possible reaction with structural water may be detrimental for the characterization of the acidic sites, while this is not expected with milder bases like pyridine. In a parallel manner, it is noteworthy that due to their basicity, many nitrogen-containing substrates, pyridine in particular, are often chosen for the gas phase evaluation of the catalysts acidity. Infrared spectroscopy of adsorbed basic molecular probes notably has largely been used to discriminate between different acidic sites[27-29]. Conversely, such measurements are not common in liquid media due to the overwhelming signal of the liquid phase in IR spectroscopy. Towards this aim, another vibrational spectroscopy, Raman spectroscopy would be more suitable to characterize the solids immersed in liquids. In the present work we will thus focus on the 
adsorption and intercalation of nitrogen-containing organic bases on several representative layered materials using Raman spectroscopy in the liquid phase.

Acidic layered materials were chosen among W compounds due to the well-known acidity of W containing oxides[30,31]. Pure tungstated layered solids $\mathrm{H}_{2} \mathrm{~W}_{2} \mathrm{O}_{7}$ and $\mathrm{H}_{2} \mathrm{WO}_{4}$ were selected for comparison with layered mixed oxides, $\mathrm{HNbWO}_{6}$ and its molybdenum counter-part $\mathrm{HNbMoO}_{6}$. The intercalation behaviour and the acidity of these materials differing by the metals present or by their structure, will be studied in presence of bases of different strength and size, pyridine and n-alkylamines.The combined use of Raman spectroscopy in the liquid phase and powder X-ray diffraction on dried materials allow the discrimination between different layered solids based on their stability and accessible acidity in intercalation conditions but also highlights the interactions between the inorganic layers and the liquid bases.

\section{Experimental Part}

2.1. Preparation of Layered hosts. Layered $\mathrm{H}_{2} \mathrm{~W}_{2} \mathrm{O}_{7}, \mathrm{H}_{2} \mathrm{WO}_{4}, \mathrm{HNbWO}_{6}$ and $\mathrm{HNbMoO}_{6}$ were prepared by proton-exchange of the precursors $\mathrm{Bi}_{2} \mathrm{~W}_{2} \mathrm{O}_{9}, \mathrm{Bi}_{2} \mathrm{WO}_{6}, \mathrm{LiNbWO}_{6}$ and $\mathrm{LiNbMoO}_{6}$, respectively, which were synthesized through a solid state-reaction method $[16,23,26,32]$.

$\mathrm{Bi}_{2} \mathrm{~W}_{2} \mathrm{O}_{9}$ was synthesized by mixing a stoichiometric amount of bismuth trioxide $\left(\mathrm{Bi}_{2} \mathrm{O}_{3}\right)$ and tungsten trioxide $\left(\mathrm{WO}_{3}\right)$ and grinding to a fine powder with a mortar and pestle. The powder was then pressed into pellets, placed on a platinum foil supported by an alumina crucible and heated at $750{ }^{\circ} \mathrm{C}$ for 20 hours to obtain a yellowish bismuth tungstate powder. Then the protonated form, $\mathrm{H}_{2} \mathrm{~W}_{2} \mathrm{O}_{7}$, was synthesized by stirring the $\mathrm{Bi}_{2} \mathrm{~W}_{2} \mathrm{O}_{9}$ precursor with $6 \mathrm{M} \mathrm{HCl}$ solution for 6 days with one replacement with a fresh solution after 3 days. The resultant solids were then centrifuged and washed several times with distilled water before drying in air at $140{ }^{\circ} \mathrm{C}[32,33]$.

For $\mathrm{Bi}_{2} \mathrm{WO}_{6}$, the stoichiometric amounts of bismuth and sodium tungstate solutions were obtained by dissolving $\mathrm{Bi}\left(\mathrm{NO}_{3}\right)_{3} .5 \mathrm{H}_{2} \mathrm{O}$ in nitric acid and $\mathrm{Na}_{2} \mathrm{WO}_{4} \cdot 2 \mathrm{H}_{2} \mathrm{O}$ in distilled water. Then the solutions were mixed together in a Teflon reactor and heated in a microwave oven at $200^{\circ} \mathrm{C}$ for 4 hours. Finally, the solid was centrifuged, washed several times with distilled water and dried under air to obtain pale yellow powder [34,35]. Protonation was carried out similarly to $\mathrm{Bi}_{2} \mathrm{~W}_{2} \mathrm{O}_{9}$.

$\mathrm{LiNbMoO}_{6}$ and $\mathrm{LiNbWO}_{6}$ were prepared by heating a stoichiometric mixture of $\mathrm{Li}_{2} \mathrm{CO}_{3}$, $\mathrm{Nb}_{2} \mathrm{O}_{5}$ and $\mathrm{MoO}_{3} / \mathrm{WO}_{3}$ at $580 / 750{ }^{\circ} \mathrm{C}$ for $24 / 72$ hours respectively. The protonated forms, 
$\mathrm{HNbMoO}_{6}$ and $\mathrm{HNbWO}_{6}$, were obtained by stirring the lithium forms with $\mathrm{HNO}_{3}(2 \mathrm{M})$ at room temperature for 3 days with one replacement of the acid solution in between. The samples were then washed several times with distilled water and air dried at $150^{\circ} \mathrm{C}$.

2.2. Intercalation procedures. The intercalation process of n-alkylamines (butylamine, octylamine) or pyridine into layered $\mathrm{HNbMoO}_{6}, \mathrm{HNbWO}_{6}, \mathrm{H}_{2} \mathrm{WO}_{4}$ and $\mathrm{H}_{2} \mathrm{~W}_{2} \mathrm{O}_{7}$ was carried out in the following manner: intercalates were added dropwise into the sample, and characterized using Raman spectroscopy in the liquid phase. After stirring, the samples were dried and characterized by means of powder X-ray diffraction pattern (PXRD) and thermogravimetry coupled with IR spectroscopy. The amounts of liquid added ranged typically from 1 drop (ca. $0.02 \mathrm{~g}$ ) to 15 drops (ca. $0.3 \mathrm{~g}$ ) for ca. $40 \mathrm{mg}$ of the solid sample. Therefore the amount of liquid ranged from ca. 0.5 to $8 \mathrm{~g}$ liquid $/ \mathrm{g}$ solid. Unless otherwise stated the final amount of the liquid was always introduced in large excess: the molar ratio $\mathrm{R}_{\mathrm{m}}=$ molar number of the liquid molecule / mol of the layered solid were finally higher than 6, typically around 10-20.PXRD data were acquired at the end of the intercalation process, hence with the highest $\mathrm{R}_{\mathrm{m}}$ ratio.

2.3. Characterization. The intercalation processes were first characterized using Raman spectroscopy in the liquid phase. This was done using an immersion Raman probe (InPhotonics) lined to the spectrometer (Horiba Jobin Yvon Labram 300) via optical fibers.A green laser at 532 $\mathrm{nm}$ wavelength was used for excitation. (Thin peaks that sometimes appear on the spectra at 417 , 576 and $751 \mathrm{~cm}^{-1}$ are due to the probe). After drying, the samples were characterized by PXRD at room temperature by using a PANalytical X'pert PRO diffractometer with $\mathrm{Cu} \mathrm{K} \alpha$ radiation $(\lambda=$ $1.54060 \AA$ ) in the $2 \theta$ range from $3^{\circ}$ to $75^{\circ}$ at $0.4^{\circ} / \mathrm{min}$ with a step width of $0.017^{\circ}$. Thermogravimetric measurements were performed at a heating rate of $5^{\circ} \mathrm{C} / \mathrm{min}$ under $40 \mathrm{~mL} / \mathrm{min}$ air flow with a Setaram Setsys apparatus, and evolved gas was simultaneously identified by monitoring FT-IR spectra.

\section{Results and Discussion}

\subsection{Influence of materials protonation upon structural and vibrational features.}

After synthesis of the starting materials $\mathrm{Bi}_{2} \mathrm{~W}_{2} \mathrm{O}_{9}, \mathrm{Bi}_{2} \mathrm{WO}_{6}, \mathrm{LiNbWO}_{6}$ and $\mathrm{LiNbMoO}_{6}$, a subsequent step of protonation is required in order to convert the as-made solid to its acidic form. 
This step modifies notably the interlayer which has a direct impact on the structural features [22]. PXRD patterns and Raman spectroscopy are used first to confirm protonation and establish the Raman signature of all synthesized materials in as-synthesized and protonated form and second to evaluate the adsorption sites for the intercalated molecules. The PXRD patterns of the precursors and their corresponding proton-exchanged samples (Supplementary information, Figure S1) agree with those reported in the literature $[22,23,26,33]$.The lattice parameters are reported in Table 1. All PXRD profiles showed sharp and single diffraction peaks and notably intense (001) reflections that are characteristics of layered structures[36]. $\mathrm{Bi}_{2} \mathrm{~W}_{2} \mathrm{O}_{9}$ and $\mathrm{Bi}_{2} \mathrm{WO}_{6}$ belong to Aurivillius phases and consist of bismuth oxide sheets and octahedral $\mathrm{ReO}_{3}$-like slabs (Figure 1). All reflections were indexed on the basis of an orthorhombic cell with a space group $P n a 2_{1}$ and $P 2_{1} a b$ for $\mathrm{Bi}_{2} \mathrm{~W}_{2} \mathrm{O}_{9}$ and $\mathrm{Bi}_{2} \mathrm{WO}_{6}$, respectively (Table 1). The difference in their c-parameter (and thus interlayer spacing) is related to the different number of perovskite slabs between the $\mathrm{Bi}_{2} \mathrm{O}_{2}$ layers (double and single for $\mathrm{Bi}_{2} \mathrm{~W}_{2} \mathrm{O}_{9}$ and $\mathrm{Bi}_{2} \mathrm{WO}_{6}$ respectively). For both $\mathrm{LiNbWO}_{6}$ and $\mathrm{LiNbMoO}_{6}$ solids, the lattice parameters were indexed on the basis of a tetragonal cell with a space group $P-42{ }_{1} m$. Their structure is reported to be constituted of randomly located $\mathrm{MO}_{6}$ and $\mathrm{NbO}_{6}$ octahedral double layers with lithium cations in the interlayers that are perpendicular to the c-axis (Figure 1) [22,37]. Despite the difference in chemical composition, both solids showed very similar lattice parameters.

After treatment with hydrochloric acid, the distance between two successive metal oxide layers along c direction (noted d-interlayer in Table 1) changed considerably compared to their corresponding precursors while in general, the in-plane ( $a$ and $b$ ) parameters were little affected. For $\mathrm{H}_{2} \mathrm{~W}_{2} \mathrm{O}_{7}$ and $\mathrm{H}_{2} \mathrm{WO}_{4}$, d-interlayer largely decreased due to selective leaching of $\mathrm{Bi}_{2} \mathrm{O}_{2}{ }^{2+}$ with $2 \mathrm{H}^{+}$[33], while the opposite change was observed for $\mathrm{HNbMoO}_{6}$ and $\mathrm{HNbWO}_{6}$, due to both the replacement of $\mathrm{Li}^{+}$with $\mathrm{H}^{+}$and the hydration of the interlayer protons [26]. Thermogravimetric analyses (Supplementary information, Figure S2) indeed showed that water was also coordinated and the general formulae of the layered solids were expressed as follows: $\mathrm{H}_{2} \mathrm{~W}_{2} \mathrm{O}_{7} \cdot 0.1 \mathrm{H}_{2} \mathrm{O}$, $\mathrm{H}_{2} \mathrm{WO}_{4} \cdot \mathrm{H}_{2} \mathrm{O}, \mathrm{HNbWO}_{6} .1 .5 \mathrm{H}_{2} \mathrm{O}$ and $\mathrm{HNbMoO}_{6} \cdot \mathrm{H}_{2} \mathrm{O}$, which is consistent with previous studies $[22,23]$. The interlayer distance is affected by the extent of hydration (Table 1) and thus by the content of the interlayer. This is illustrated with $\mathrm{HNbWO}_{6}$ for which the d-interlayer decreases by $2 \AA$ when the amount of water is decreased. 
a)

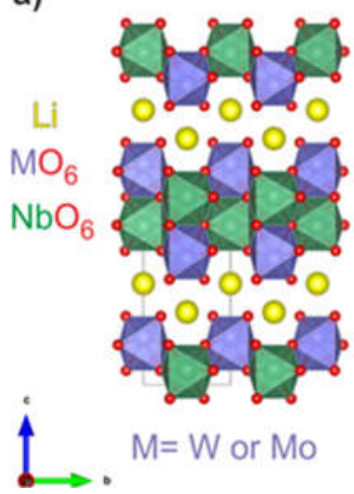

b)

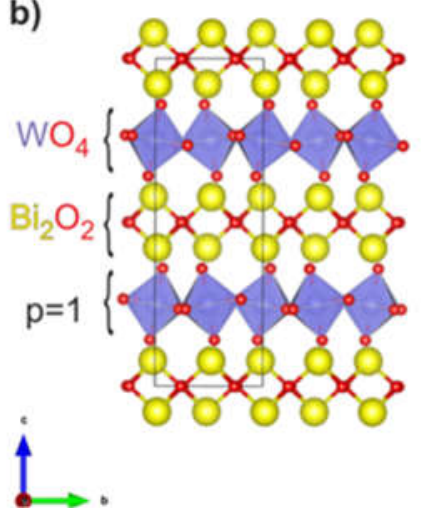

c)

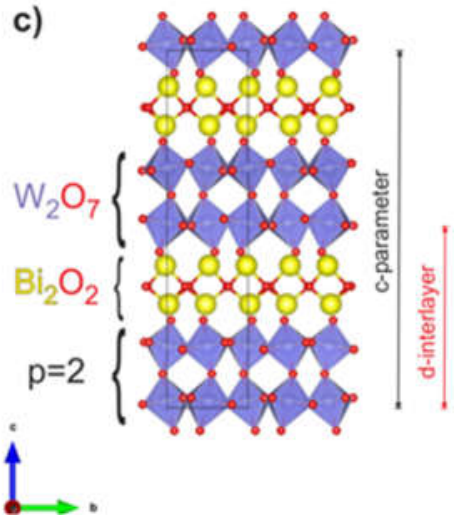

Figure 1. Crystal structure of (a) $\mathrm{LiNbMO}_{6}\left(\mathrm{M}=\mathrm{Mo}\right.$, W), (b) $\mathrm{Bi}_{2} \mathrm{WO}_{6}$ and (c) $\mathrm{Bi}_{2} \mathrm{~W}_{2} \mathrm{O}_{9}$. The integer $\mathrm{p}$ corresponds to the number of layers $\left(\mathrm{WO}_{4}\right.$ or $\left.\mathrm{W}_{2} \mathrm{O}_{7}\right)$ intercalated between $\mathrm{Bi}_{2} \mathrm{O}_{2}{ }^{2+}$ sheets. The spacing existing between two octahedral layers is noted as d-interlayer.

Table 1. Lattice parameters of the as-synthesized solids and their proton exchanged phases.

Lattice parameters $(\AA)$

\begin{tabular}{lcccc}
\hline Compound & $\mathrm{a}$ & $\mathrm{b}$ & $\mathrm{c}$ & $\mathrm{d}$-interlayer \\
\hline $\mathrm{Bi}_{2} \mathrm{~W}_{2} \mathrm{O}_{9}$ & $5.4346(3)$ & $5.4137(1)$ & $23.693(2)$ & 11.85 \\
$\mathrm{H}_{2} \mathrm{~W}_{2} \mathrm{O}_{7}$ & $5.197(2)$ & $5.064(3)$ & $18.32(1)$ & 9.16 \\
$\mathrm{Bi}_{2} \mathrm{WO}_{6}$ & $5.450(2)$ & $5.445(2)$ & $16.525(6)$ & 8.26 \\
$\mathrm{H}_{2} \mathrm{WO}_{4} \cdot \mathrm{H}_{2} \mathrm{O}$ & $5.344(5)$ & $5.241(4)$ & $13.72(1)$ & 6.86 \\
$\mathrm{LiNbWO}_{6}$ & $4.6831(3)$ & $4.6831(3)$ & $9.2792(6)$ & 9.28 \\
$\mathrm{HNbWO}_{6} .0 .5 \mathrm{H}_{2} \mathrm{O}$ & $4.7157(9)$ & $4.7157(9)$ & $20.77(1)$ & 10.39 \\
$\mathrm{HNbWO}_{6} 1.5 \mathrm{H}_{2} \mathrm{O}$ & $4.733(2)$ & $4.733(2)$ & $25.47(3)$ & 12.73 \\
$\mathrm{LiNbMoO}_{6}$ & $4.6917(7)$ & $4.6917(7)$ & $9.243(2)$ & 9.24 \\
$\mathrm{HNbMoO}_{6} \cdot \mathrm{H}_{2} \mathrm{O}$ & $4.664(2)$ & $4.664(2)$ & $26.293(2)$ & 13.15 \\
\hline
\end{tabular}

As several layered materials were used in this work, pure tungstates and mixed oxides, it is interesting to compare, using Raman spectroscopy, the vibrational features of all these materials and their evolution after protonation. The spectra of the precursors and protonated solids are shown in Figure 2. The main Raman peaks and their attributions are listed in Table 2. $\mathrm{Bi}_{2} \mathrm{~W}_{2} \mathrm{O}_{9}$ and $\mathrm{Bi}_{2} \mathrm{WO}_{6}$, showed their main bands around $800 \mathrm{~cm}^{-1}$ due to $\mathrm{WO}$ bonds within the perovskitelike layers. The peaks at higher Raman shifts for $\mathrm{Bi}_{2} \mathrm{~W}_{2} \mathrm{O}_{9}$ compared to $\mathrm{Bi}_{2} \mathrm{WO}_{6}$ are likely due to the difference in the length of W-O bonds for the apical atoms [38]. For both solids, the $\mathrm{Bi}_{2} \mathrm{O}_{2}{ }^{2+}$ 
layers are relatively similar. From the works of Gupta et al. [39] and Mạczka et al.[38], the band at $416 \mathrm{~cm}^{-1}$ might be assigned to $v(\mathrm{Bi}-\mathrm{O})$ while several bands below $330 \mathrm{~cm}^{-1}$ may be assigned to the bending modes of the $\mathrm{WO}_{6}$ octahedra and $\left(\mathrm{Bi}_{2} \mathrm{O}_{2}\right)^{2+}$ layers. In particular the larger bands at ca. 324 and $309-305 \mathrm{~cm}^{-1}$ are likely due to $\mathrm{Bi}-\mathrm{O}$ vibrations.

Protonation induced major changes on the Raman spectra. For both $\mathrm{Bi}_{2} \mathrm{~W}_{2} \mathrm{O}_{9}$ and $\mathrm{Bi}_{2} \mathrm{WO}_{6}$, the bands related to the presence of bismuth at ca. 416, 324 and 309-305 $\mathrm{cm}^{-1}$ disappeared, confirming their assignments and indicating the complete protonation of the solids. Other changes were also observed. The peaks attributed to WO stretching vibrations around $800-950 \mathrm{~cm}^{-1}$ were blue shifted upon protonation due to the formation of tungsten compounds with lower coordination numbers, as previously observed [40,41]. Meanwhile, a new broad band develops around $670 \mathrm{~cm}^{-1}$. This band, attributed to $v(\mathrm{OWO})$ vibration, is significantly affected by hydration and can be used to identify the hydration level of crystals [42-44]. It should be noted that $\mathrm{H}_{2} \mathrm{WO}_{4}$ is not very stable in this state. Further dehydration, obtained for example by the use of full laser power yielded the quick formation of dehydrated bulk $\mathrm{WO}_{3}$ which is easily detected by its characteristic Raman spectrum. In this case, intense bands were observed at 802, 708, 324 and 263 $\mathrm{cm}^{-1}$.

The two mixed oxides $\mathrm{LiNbMoO}_{6}$ and $\mathrm{LiNbWO}_{6}$ can be compared with each other. They showed similar spectra with clear distinctions between the vibrations due to $\mathrm{Nb}$ and those due to Mo or W. Notably the $v(\mathrm{Mo}=\mathrm{O})$ or $v(\mathrm{~W}=\mathrm{O})$ bands situated at 932 and $957 \mathrm{~cm}^{-1}$ for $\mathrm{LiNbMoO}_{6}$ and $\mathrm{LiNbWO}_{6}$ respectively and the $v(\mathrm{Nb}=\mathrm{O})$ bands at 864 and $885 \mathrm{~cm}^{-1}$ for $\mathrm{LiNbMoO}_{6}$ and $\mathrm{LiNbWO}_{6}$ respectively are clearly separated. Although both solids have a similar structure, the position of these latter $v(\mathrm{Nb}=\mathrm{O})$ bands appears influenced by the surrounding metal [26]. The bands at lower Raman shifts, assigned to deformation vibrations, only show slight differences between the two solids, for either the position or the relative intensities. When the interlayer cations $\left(\mathrm{Li}^{+}\right)$were exchanged with $\mathrm{H}^{+}$after acid treatment, bands corresponding to the stretching vibration of $\mathrm{Mo}=\mathrm{O}$ and $\mathrm{W}=\mathrm{O}$, as well as $\mathrm{Nb}=\mathrm{O}$ and $\mathrm{Nb}-\mathrm{O}-\mathrm{M}$, shifted to higher frequencies for both $\mathrm{HNbMoO}_{6}$ and $\mathrm{HNbWO}_{6}$. Simultaneously, the bending vibrations of $\mathrm{MO}_{6}$ or $\mathrm{M}-\mathrm{O}$ displayed in the range $400-100 \mathrm{~cm}^{-1}$ shifted to lower frequencies in both samples. For instance, bending vibration of $\mathrm{MO}_{6}$ shifted from 408 and $407 \mathrm{~cm}^{-1}$ in $\mathrm{LiNbMoO}_{6}$ and $\mathrm{LiNbWO}_{6}$ to 369 and $358 \mathrm{~cm}^{-1}$ respectively after protonation. This reveals the significant effect of the interlayer cations on the framework of these solids. 

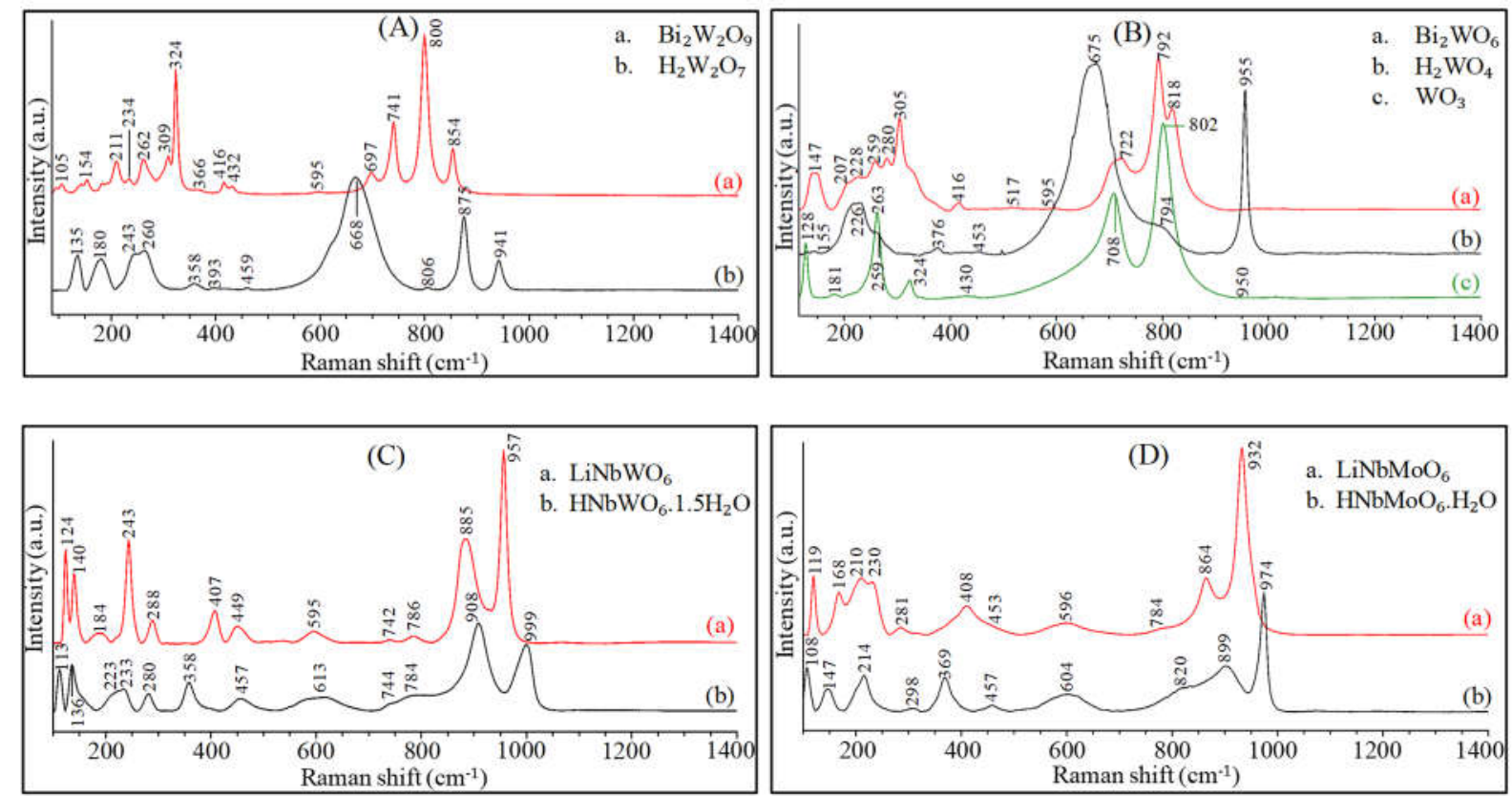

Figure 2. Raman spectra of the parent precursors (a) and the protonated samples (b) for (A) $\mathrm{Bi}_{2} \mathrm{~W}_{2} \mathrm{O}_{9}$, (B) $\mathrm{Bi}_{2} \mathrm{WO}_{6}$, (C) $\mathrm{LiNbWO}_{6}$ and (D) $\mathrm{LiNbMoO}_{6}$. In graph (B), spectrum (c): $\mathrm{WO}_{3}$ is obtained after decomposition of $\mathrm{H}_{2} \mathrm{WO}_{4}$.

For all these layered materials, protonation induced noticeable changes of the Raman spectra. This highlights the modifications of the interactions at the slabs surface and in the interlayer. Such characterization can thus be used to monitor the interactions of layered solids with intercalating molecules, as developed in the following sections. 
Table 2. Detailed peak positions $\left(\Delta v / \mathrm{cm}^{-1}\right)$ and their assignments for all samples. The protonated samples are indicated in bold. These assignments were tentatively made, based principally on the cited references. Notations were unified here between the samples for clarity.

\begin{tabular}{|c|c|c|c|c|c|c|c|c|c|}
\hline & \multicolumn{9}{|c|}{ Raman shift $\left(\mathrm{cm}^{-1}\right)$} \\
\hline & $\mathrm{LiNbMoO}_{6}$ & $\mathrm{HNbMoO}_{6}$ & $\mathrm{LiNbWO}_{6}$ & $\mathrm{HNbWO}_{6}$ & $\mathrm{Bi}_{2} \mathrm{~W}_{2} \mathrm{O}_{9}$ & $\mathbf{H}_{2} \mathbf{W}_{2} \mathbf{O}_{7}$ & $\mathrm{Bi}_{2} \mathrm{WO}_{6}$ & $\mathrm{H}_{2} \mathrm{WO}_{4}$ & $\mathrm{WO}_{3}$ \\
\hline Reference & {$[45]$} & [45] & [46] & {$[46]$} & {$[38,39]$} & [47] & {$[38,48]$} & [48] & {$[44,47]$} \\
\hline$v(\mathrm{M}=\mathrm{O})^{\mathrm{a}}$ & 932 & 974 & 957 & 999 & $854-800$ & $941-875$ & $818-792$ & 955 & 950 \\
\hline$v(\mathrm{Nb}=\mathrm{O})$ & 864 & 899 & 885 & 908 & & & & & \\
\hline$v(\mathrm{M}-\mathrm{O}-\mathrm{M})^{\mathrm{a}} / \mathrm{v}(\mathrm{O}-\mathrm{M}-\mathrm{O})$ & 784 & 820 & $786-742$ & $784-744$ & $741-697$ & $806-668$ & 722 & $\begin{array}{l}794 \\
675\end{array}$ & $\begin{array}{l}802 \\
708\end{array}$ \\
\hline$v(\mathrm{Nb}-\mathrm{O}-\mathrm{M})^{\mathrm{a}}$ & 596 & 604 & 595 & 613 & & & & & \\
\hline $\mathrm{v}(\mathrm{O}-\mathrm{Nb}-\mathrm{O})$ & 453 & 457 & 449 & 457 & & & & & \\
\hline$\delta\left(\mathrm{MO}_{6}\right)^{\mathrm{a}}$ & 408 & 369 & 407 & 358 & $432-366$ & $\begin{array}{c}459-393- \\
358\end{array}$ & 370 & $\begin{array}{c}453- \\
376\end{array}$ & 430 \\
\hline $\begin{array}{l}\delta(\mathrm{M}-\mathrm{O}-\mathrm{Nb}) / \delta(\mathrm{M}- \\
\mathrm{O}-\mathrm{M})^{\mathrm{a}}\end{array}$ & 281 & 298 & 288 & 280 & 262 & $260-243$ & $280-259$ & & $324-263$ \\
\hline$\delta(\mathrm{O}-\mathrm{Nb}-\mathrm{O})$ & $230-210$ & 214 & 243 & $233-223$ & & & & & \\
\hline$\delta\left(\mathrm{NbO}_{6}\right)$ & 168 & 147 & 184 & 136 & & & & & \\
\hline$v(\mathrm{Bi}-\mathrm{O})$ & & & & & 416 & & 416 & & \\
\hline$\delta\left(\mathrm{WO}_{6}\right)+\delta\left(\mathrm{Bi}_{2} \mathrm{O}_{2}{ }^{2+}\right)$ & & & & & $\begin{array}{c}324-309- \\
234-211\end{array}$ & & $\begin{array}{c}330-305- \\
228-207\end{array}$ & & \\
\hline
\end{tabular}




\subsection{Highlighting the intercalation process in protonated layered oxides}

In view of the ability of layered materials to intercalate molecules, the characterization of the intercalation process is necessary. Upon introduction of a molecule on the solid, several modifications can occur, from the mere interaction with the slab surface to more extensive perturbations of the structure of the layered material. Besides, intercalation may occur to very different extents depending on the solid and the molecule but also on its arrangement in the interlayer. Nitrogen-containing substrates are often used in intercalation studies, notably primary amines which may give rise to large expansions. These molecules are thus interesting to study as reference and their strong basicity is likely to favour their intercalation within all the layered solids studied here. Nevertheless, this basicity may also induce noticeable transformations of the solid. Indeed, previous studies by Chen et al. $[49,50]$ have proposed that in presence of n-alkylamines, $\mathrm{H}_{2} \mathrm{~W}_{2} \mathrm{O}_{7}$ may be modified by a possible dissolutionreorganization mechanism of the double-octahedral $\mathrm{W}-\mathrm{O}$ layers of this solid and the restackings of single W-O octahedral layers, similarly to what could be observed for $\mathrm{H}_{2} \mathrm{WO}_{4}$. In this case, our direct characterization by Raman spectroscopy in liquid phase with butylamine or octylamine, will highlight the evolution of the solid including in conditions where the solid is possibly modified. This also indicates to what extent these amines may discriminate between the layered acidic oxides.

PXRD patterns (Supplementary Information, Figure S3) provide evidence of the intercalation process by monitoring the evolution of the interlayer spacing. The d-interlayer values reported inTable 3 indicate that intercalation of n-alkylamines was successfully achieved with an increase of interlayer spacing for all solids. Noticeably, despite their different initial values, the interlayer spacings for $\mathrm{H}_{2} \mathrm{~W}_{2} \mathrm{O}_{7}$ and $\mathrm{H}_{2} \mathrm{WO}_{4}$ were found strictly similar after intercalation. Interlayer spacings also increased for all the solids with the chain length of the intercalated molecule (Table 3). The interlayer spacing increased much more when the amines where intercalated in the purely tungstate phases (the relative increase was $+184 \%$ and $280 \%$ when octylamine was intercalated into $\mathrm{H}_{2} \mathrm{~W}_{2} \mathrm{O}_{7}$ and $\mathrm{H}_{2} \mathrm{WO}_{4}$ respectively, while it was only $+140 \%$ and $+117 \%$ when it was intercalated into $\mathrm{HNbWO}_{6}$ and $\mathrm{HNbMoO}_{6}$ respectively). This could indicate differences in the intercalation mechanism between the two series of layered solids. 
Table 3. Interlayer spacings of the solids before and after interaction with butylamine and octylamine.

\begin{tabular}{lccc}
\cline { 2 - 4 } Compound & \multicolumn{3}{c}{ d-interlayer $(\AA)$} \\
\hline $\mathrm{H}_{2} \mathrm{~W}_{2} \mathrm{O}_{7} .0 .1 \mathrm{H}_{2} \mathrm{O}$ & $9.16(1)$ & $16.20(1)$ & $26.04(1)$ \\
$\mathrm{H}_{2} \mathrm{WO}_{4} \cdot \mathrm{H}_{2} \mathrm{O}$ & $6.86(1)$ & $16.08(3)$ & $26.06(1)$ \\
$\mathrm{HNbWO}_{6} .1 .5 \mathrm{H}_{2} \mathrm{O}$ & $12.73(3)$ & $20.18(3)$ & $30.6(1)$ \\
$\mathrm{HNbMoO}_{6} \cdot \mathrm{H}_{2} \mathrm{O}$ & $13.15(1)$ & $20.49(4)$ & $28.6(1)$ \\
\hline
\end{tabular}

Based on the geometrical analysis made by Chen et al. $[49,50]$ the arrangement of the amines in the interlayer and the thickness of the inorganic layer involved were evaluated (Supplementary information, section 2). This analysis indicates that for both $\mathrm{H}_{2} \mathrm{~W}_{2} \mathrm{O}_{7}$ and $\mathrm{H}_{2} \mathrm{WO}_{4}$, a bilayer arrangement of the amine is observed and that the thickness of the inorganic layer after intercalation/reaction with the n-alkylamine is evaluated at ca. $0.40 \mathrm{~nm}$ for $\mathrm{H}_{2} \mathrm{~W}_{2} \mathrm{O}_{7}$ and $0.37 \mathrm{~nm}$ for $\mathrm{H}_{2} \mathrm{WO}_{4}$. These values are close to a single octahedral tungstate layer $(0.41 \mathrm{~nm}[50])$ as expected for $\mathrm{H}_{2} \mathrm{WO}_{4}$ but not for $\mathrm{H}_{2} \mathrm{~W}_{2} \mathrm{O}_{7}$, which is initially constituted of double layers of octahedral tungstates. Therefore, the two solids tend to be nearly equivalent after amine intercalation. To ascertain this was not the case for the other layered materials, the same methodology was applied here for the mixed oxides $\mathrm{HNbWO}_{6}$ and $\mathrm{HNbMoO}_{6}$ (Supplementary information, section 2). The thickness of the inorganic layers was evaluated at 0.74 and $0.95 \mathrm{~nm}$, respectively. These values are approximately two times the value of a single octahedral tungstate layer which indicates that these two solids still show their original ( $\mathrm{W}(\mathrm{Mo}) \mathrm{O}_{6}+\mathrm{NbO}_{6}$ ) octahedral double layers. By contrast to $\mathrm{H}_{2} \mathrm{~W}_{2} \mathrm{O}_{7}$, the mixed oxide solids appear stable as they are not modified upon amine intercalation.

In view of these different behaviours towards amine intercalation, the comparison of the Raman spectra of the two series can bring additional information on the respective mechanisms of intercalation and on the possible degradation of $\mathrm{H}_{2} \mathrm{~W}_{2} \mathrm{O}_{7}$. Only the results concerning octylamine intercalation are discussed here, but similar results were found for butylamine (see Supplementary information, Figures S7-S11). 


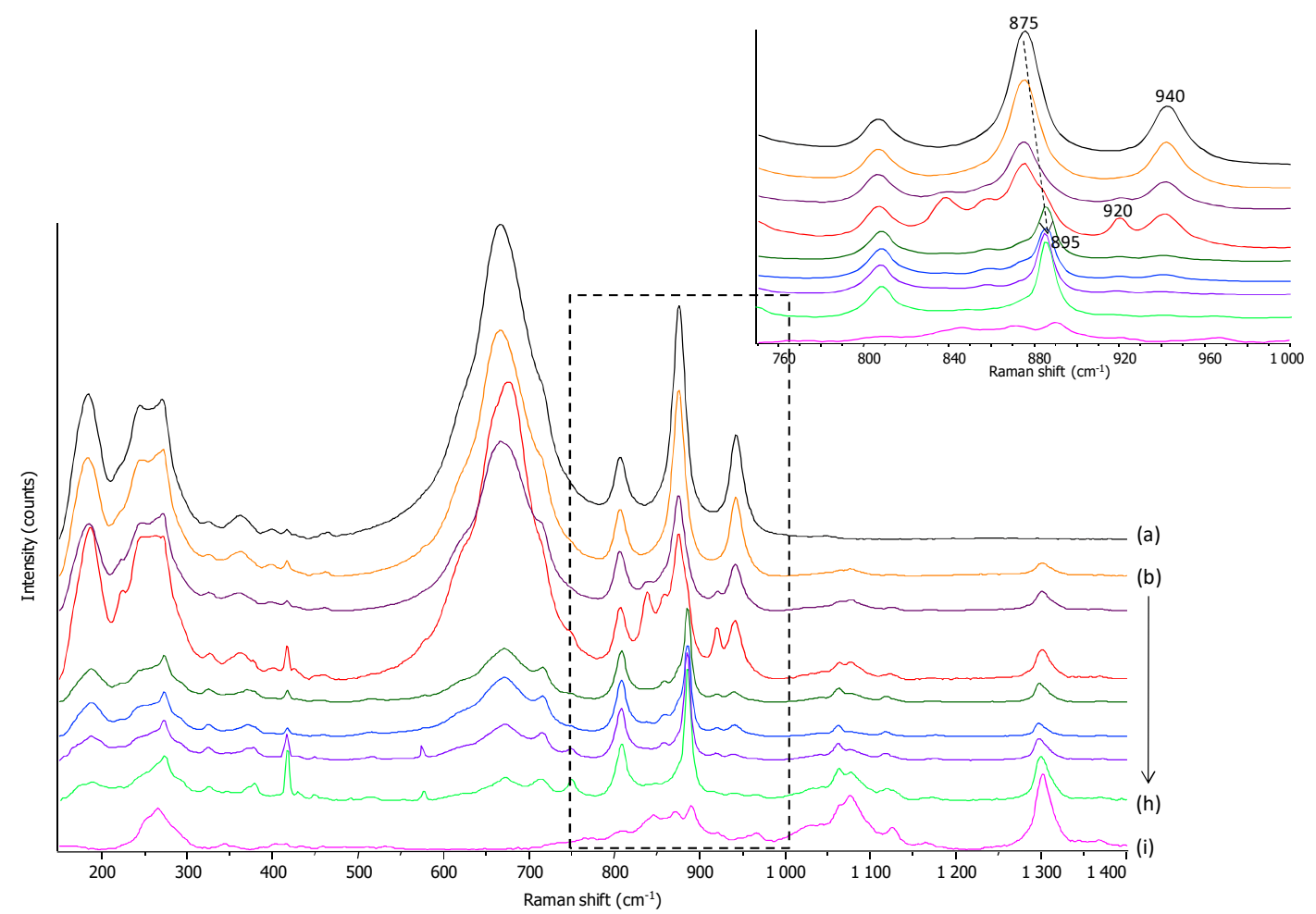

Figure 3. Raman spectra of octylamine intercalation on (a) $\mathrm{H}_{2} \mathrm{~W}_{2} \mathrm{O}_{7}$ and (b - h) evolution with time (from15 min to 12 days) of $\mathrm{H}_{2} \mathrm{~W}_{2} \mathrm{O}_{7}$ after adding increasing amounts of octylamine (Molar ratio $R_{m}=2$ - 26); (i) pure liquid octylamine. The inset shows the enlargement at (750 $-1000 \mathrm{~cm}^{-1}$ ). For comparison, spectra (a) to (h) were normalized to the band at $805 \mathrm{~cm}^{-1}$.

In presence of octylamine the Raman spectra of $\mathrm{H}_{2} \mathrm{~W}_{2} \mathrm{O}_{7}$ evolved progressively (Figure 3): the $v(\mathrm{~W}=\mathrm{O})$ band at $942 \mathrm{~cm}^{-1}$ decreased and shifted to $920 \mathrm{~cm}^{-1}$. This occurred parallel to changes on the amine bands with some additional perturbations in the $v(\mathrm{C}-\mathrm{H})$ bands. Then, the bands at $920-942 \mathrm{~cm}^{-1}$ progressively disappeared while the band at 875 shifted to $895 \mathrm{~cm}^{-1}$ and the broad band at $670 \mathrm{~cm}^{-1}$ finally decreased markedly. Meanwhile, bands at 805,714 and $268 \mathrm{~cm}^{-1}$ became clearly visible. This set of bands can be ascribed to the presence of $\mathrm{WO}_{3}[44,51]$ while bands around $900 \mathrm{~cm}^{-1}$ may be found for $\mathrm{WO}_{4}$ compounds $[52,53]$. This coherent changes imply that the amine interacts first with the apical $\mathrm{W}=\mathrm{O}$ of $\mathrm{H}_{2} \mathrm{~W}_{2} \mathrm{O}_{7}$. Meanwhile, the perturbation of the $v(\mathrm{OWO})$ vibration by water at $670 \mathrm{~cm}^{-1}$ was suppressed after amine intercalation, which indicates that water was removed from these sites. At the same time, $\mathrm{NH}_{2}$ antisymmetric and symmetric bands of pure octylamine located at 3380 and $3325 \mathrm{~cm}^{-1}$ decreased in intensity and a new band arouse at ca. $3095 \mathrm{~cm}^{-1}$ (Supplementary Information, Figure S5). 
Interestingly, similar features were observed after intercalation of octylamine into $\mathrm{H}_{2} \mathrm{WO}_{4}$ (Figure 4). The peaks located at 957, 670 and $215 \mathrm{~cm}^{-1}$ decreased dramatically, while new sets of peaks appeared at $885,807,746,675$ and $380 \mathrm{~cm}^{-1}$ in addition to the peaks of octylamine (notably at 1070 and $1300 \mathrm{~cm}^{-1}$ ). These peaks finally slightly shifted with time to lower wavenumbers as represented in Figure 4. Noteworthy, in this case, no intermediate state is observed (bands at $920 \mathrm{~cm}^{-1}$ were not observed).

Simultaneously, the antisymmetric and symmetric $(\mathrm{NH})$ bands of pure octylamine or butylamine located at 3379 and $3325 \mathrm{~cm}^{-1}$ decreased and a new peak at ca. $3104 \mathrm{~cm}^{-1}$ emerged (Supplementary Information, Figure S6). This is attributed to the protonation of the amine groups to form ammonium ions which was shown to occur after reaction with water intercalated within the interlayers [54,55].

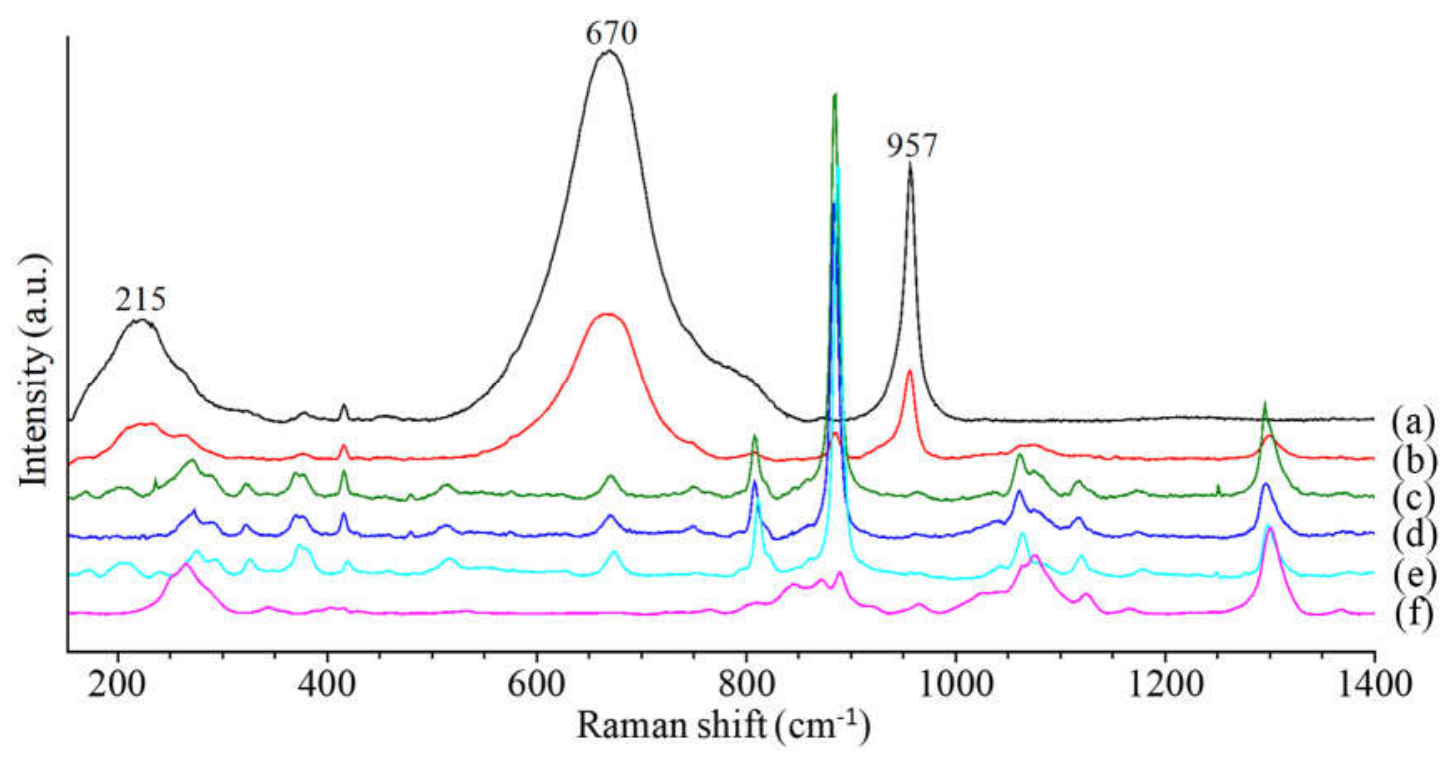

Figure 4. Raman spectra of octylamine intercalation on (a) $\mathrm{H}_{2} \mathrm{WO}_{4}$ and (b - e) evolution with time (20 min to 4 months) of $\mathrm{H}_{2} \mathrm{WO}_{4}$ after adding increasing amounts of octylamine $\left(\mathrm{R}_{\mathrm{m}}=5\right.$ 12); (f) pure liquid octylamine.

Overall, the spectra after octylamine intercalation were very similar on $\mathrm{H}_{2} \mathrm{~W}_{2} \mathrm{O}_{7}$ and $\mathrm{H}_{2} \mathrm{WO}_{4}$ which confirms that in presence of n-alkylamines, $\mathrm{H}_{2} \mathrm{~W}_{2} \mathrm{O}_{7}$ is strongly perturbed by changes in the interlayer to finally resemble $\mathrm{H}_{2} \mathrm{WO}_{4}$. It may be inferred that the simultaneous interaction with amine on both sides of the inorganic slabs decreases the strength of the bonds occurring between the two successive inorganic monolayers, first yielding an intermediate state before attaining a final state resembling that of $\mathrm{H}_{2} \mathrm{WO}_{4}$. Besides, protonation of the amine can also occur after reaction of the amines with the coordination water of $\mathrm{H}_{2} \mathrm{~W}_{2} \mathrm{O}_{7}$ 
rather than water of the interlayers. Indeed, lower amounts of intercalated water were found for $\mathrm{H}_{2} \mathrm{~W}_{2} \mathrm{O}_{7}(0.1 \mathrm{~mol} / \mathrm{mol})$ compared to those measured for $\mathrm{H}_{2} \mathrm{WO}_{4}(1 \mathrm{~mol} / \mathrm{mol})$. Therefore, the Raman spectroscopy results are consistent with the phenomenon only indirectly suggested by PXRD.

By contrast, the intercalation of amines on the layered mixed oxides did not induce any major change. Raman spectra of the $\mathrm{HNbMoO}_{6}$ and $\mathrm{HNbWO}_{6}$ solids in presence of octylamine are shown in Figure 5 (Supplementary Information, Figure S11 for butylamine). Changes were quickly observed, after adding the first few drops of octylamine, but hardly any further changes occurred although the solid was left in solution for up to one month to ascertain intercalation could effectively occur. The spectra indicated that both the bands corresponding to $\mathrm{M}=\mathrm{O}(\mathrm{M}=\mathrm{Mo}$ and $\mathrm{W})$ and $\mathrm{Nb}=\mathrm{O}$ vibrations present a slight displacement from 972 and 904 to 964 and $892 \mathrm{~cm}^{-1}$ in case of $\mathrm{HNbMoO}_{6}$ and from 990 and 906 to 972 and $894 \mathrm{~cm}^{-1}$ in case of $\mathrm{HNbWO}_{6}$. This implies that amine interacts similarly with both WO $(\mathrm{MoO})$ and $\mathrm{NbO}$ apical bonds from the catalysts lattice. Meanwhile, the amine spectrum was also modified around $3300 \mathrm{~cm}^{-1}$, as $\mathrm{NH}_{2}$ antisymmetric and symmetric $v(\mathrm{~N}-\mathrm{H})$ stretching bands at 3380 and $3325 \mathrm{~cm}^{-1}$ [56] decreased with the development of a band around (3080$3100 \mathrm{~cm}^{-1}$ ) due to the protonation of the amine groups by acid sites in the interlayers to form ammonium ions. This interaction demonstrates the adsorption of n-alkylamines in the interlayer region of the protonated samples. This also implies that acidic sites are in the close vicinity of $\mathrm{Mo}(\mathrm{W})=\mathrm{O}$ or $\mathrm{Nb}=\mathrm{O}$ bonds.
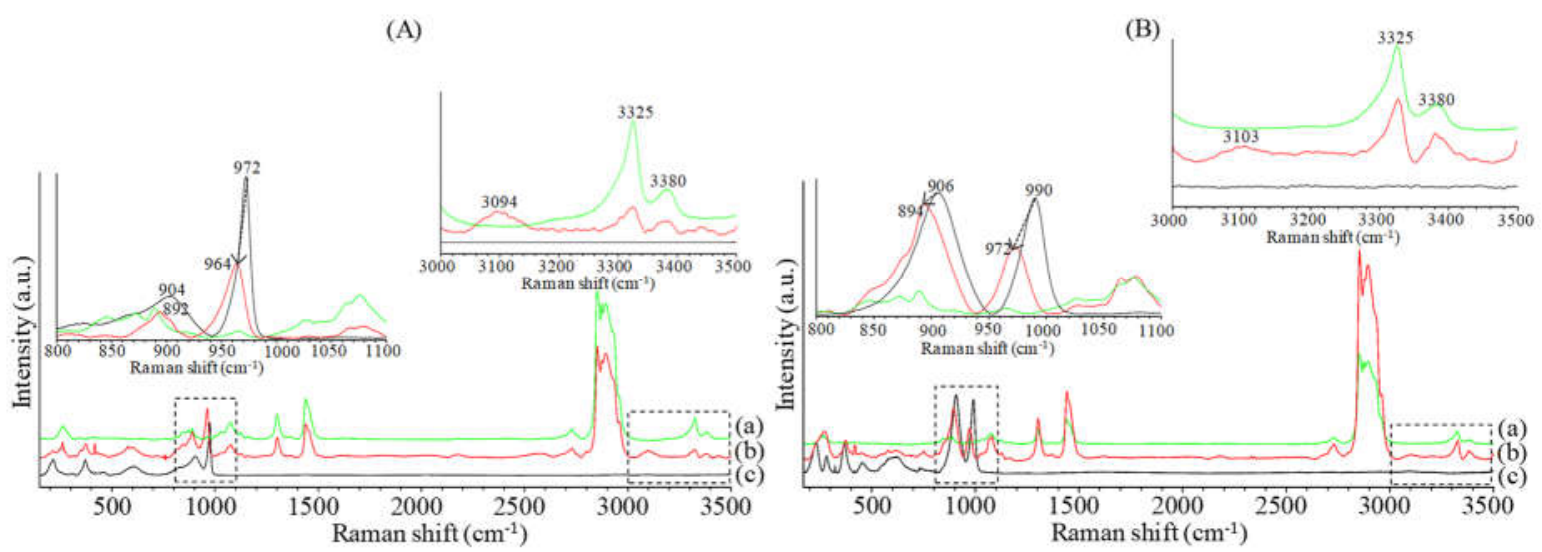

Figure 5. Full range Raman spectra $\left(200-3500 \mathrm{~cm}^{-1}\right)$ of (a) octylamine, (b) Protonated sample + octylamine $\left(R_{m}>10\right)$ and (c) Protonated sample before intercalation for (A): $\mathrm{HNbMoO}_{6}$ and (B) $\mathrm{HNbWO}_{6}$. The insets show enlargements of the spectra in $\left(800-1100 \mathrm{~cm}^{-}\right.$ $\left.{ }^{1}\right)$ and $\left(3000-3500 \mathrm{~cm}^{-1}\right)$ regions. 
Similar shifts to lower Raman wavenumbers were observed after adding butylamine into $\mathrm{HNbMoO}_{6}$ and $\mathrm{HNbWO}_{6}$ samples for the bands of the host solid and of the amine (Supplementary Information, Figure S11). As a consequence, the bands of the layered sample located at 974 and $902 \mathrm{~cm}^{-1}$ in case of $\mathrm{HNbMoO}_{6}$ shifted to 966 and $896 \mathrm{~cm}^{-1}$ after amine addition and that of $\mathrm{HNbWO}_{6}$ shifted from 990 and 905 to 976 and $899 \mathrm{~cm}^{-1}$ respectively. Moreover, pure amine bands located at 3326 and $3379 \mathrm{~cm}^{-1}$ decreased in intensity and a band around $3080-3100 \mathrm{~cm}^{-1}$ emerged.

Therefore, as indicated by PXRD, both amines were intercalated into all layered solids and resulted in acid-base interactions in the interlayers, in coherence with their strong base character and Raman spectroscopy directly follows their interactions with the solids. Nevertheless, although intercalation is achieved in all cases, the use of such strong bases did not allow any clear discrimination between the acidities of the various layered solids. Besides, their use is detrimental to a solid like $\mathrm{H}_{2} \mathrm{~W}_{2} \mathrm{O}_{7}$ due to reaction with structural water. Conversely, Raman showed the stability of the mixed layered oxides in such conditions.

\subsection{Acid sites characterization in conditions of intercalation}

Pyridine, which is a weaker base and a bulkier molecule, was selected to test its influence on intercalation and possible adsorption on the acidic sites.

The interlayer variations obtained from the PXRD patterns of the solids before and after pyridine intercalation are reported in Table 4 (see also Supplementary Information, Figure S12). PXRD results revealed that pyridine intercalated into the interlayers of pyridine into the protonated $\mathrm{HNbMoO}_{6}$ and $\mathrm{HNbWO}_{6}$ samples (Table 4). Additionally, the diffraction peaks such as (110) related to a distance within the metal oxide layers (intralayers) are observed at the same position in both cases. This indicated that only the interlayer distance is expanded with marginal modification inside the metal oxide layers. The interlayer expansion was much more limited than with the amines.

By contrast to the latter results with the protonated $\mathrm{HNbMoO}_{6}$ and $\mathrm{HNbWO}_{6}$, the reaction of $\mathrm{H}_{2} \mathrm{~W}_{2} \mathrm{O}_{7}$ with pyridine exhibited no change in the PXRD pattern as observed in Figure S12-C. In these conditions, pyridine could not be intercalated in this material. This was not the case for $\mathrm{H}_{2} \mathrm{WO}_{4}$ where expansion of the interlayer was observed. Pyridine is better suited for characterization than amines as it did not convert the solid $\mathrm{H}_{2} \mathrm{~W}_{2} \mathrm{O}_{7}$ to $\mathrm{H}_{2} \mathrm{WO}_{4}$. 
Table 4. Lattice parameters of $\mathrm{H}_{2} \mathrm{WO}_{4}, \mathrm{HNbWO}_{6}$ and $\mathrm{HNbMoO}_{6}$ before and after adding pyridine.

\begin{tabular}{lcc}
\cline { 2 - 3 } Compound & \multicolumn{2}{c}{ d-interlayer $(\AA)$} \\
\hline $\mathrm{H}_{2} \mathrm{WO}_{4} \cdot \mathrm{H}_{2} \mathrm{O}$ & $6.86(1)$ & $11.46(2)$ \\
$\mathrm{HNbWO}_{6} .1 .5 \mathrm{H}_{2} \mathrm{O}$ & $10.39(1)$ & $13.71(1)$ \\
$\mathrm{HNbMoO}_{6} \cdot \mathrm{H}_{2} \mathrm{O}$ & $13.15(1)$ & $15.06(1)$ \\
\hline
\end{tabular}

Sasaki et al. [57] have summarized possible spacings for the intercalation of pyridine : when pyridine is inserted flat (parallel to the inorganic layer), the interlayer spacing is evaluated at ca. $3 \AA$ while it is ca. $5.8 \AA$ when pyridine is intercalated perpendicular to the surface (either interacting through the ring or through the $\mathrm{N}$-atom). For both $\mathrm{HNbMoO}_{6}$ and $\mathrm{HNbWO}_{6}$, the increase is around $2 \AA$ suggesting a flat orientation. By contrast, $\mathrm{H}_{2} \mathrm{WO}_{4}$ presents a larger increase of $4.6 \AA$ which could indicate a nearly perpendicular orientation of pyridine compared to the inorganic layers (Supplementary Information, Figure S13).

For the former solids, Raman spectroscopy was used to probe more specifically the interactions of pyridine with the layered solids and also evaluate whether the acidic sites in the interlayers are accessible in the liquid phase.

Unperturbed pyridine is observed by Raman spectroscopy at 991 and $1031 \mathrm{~cm}^{-1}$. These bands are due to the $v_{1}$ and $v_{12}$ modes of ring-breathing vibrations $v(\mathrm{CCN})$, Respectively. They have been shown to shift depending on the acid sites interacting with pyridine. Notably the $v_{1}$ mode can shift from 990 to $1030 \mathrm{~cm}^{-1}$ depending on the material and the type of acidity, Brønsted or Lewis [58].

In the case of $\mathrm{H}_{2} \mathrm{~W}_{2} \mathrm{O}_{7}$, by contrast with the other solids (see below), no changes were observed in the Raman spectra (Figure 6). Bands due to $\mathrm{H}_{2} \mathrm{~W}_{2} \mathrm{O}_{7}$ and pyridine simply add to each other without any shift in the original bands of the host sample or appearance of any new peaks. Interestingly, even the band at $670 \mathrm{~cm}^{-1}$ was not affected revealing the absence of interaction between pyridine and water at the interlayer. These results confirmed the absence of intercalation or interaction between pyridine and this solid as shown by PXRD patterns. 
This also implies that eventual outer acidic sites located at the crystal surface are also too weak to protonate pyridine. Indeed, in view of the basicities of pyridine $\left(\mathrm{pk}_{\mathrm{b}}=8.82\right)$ and $\mathrm{n}$ alkylamines $\left(\mathrm{pk}_{\mathrm{b}}=3.35-3.40\right)$, it can be inferred that the basicity of pyridine is not large enough to interact with $\mathrm{H}_{2} \mathrm{~W}_{2} \mathrm{O}_{7}$ acidic sites which prohibits pyridine intercalation. $\mathrm{H}_{2} \mathrm{~W}_{2} \mathrm{O}_{7}$ surface sites are thus weakly acidic. The successful intercalation of pyridine into $\mathrm{H}_{2} \mathrm{WO}_{4}$, $\mathrm{HNbMoO}_{6}$ and $\mathrm{HNbWO}_{6}$ might be related to stronger acid sites compared to $\mathrm{H}_{2} \mathrm{~W}_{2} \mathrm{O}_{7}$.
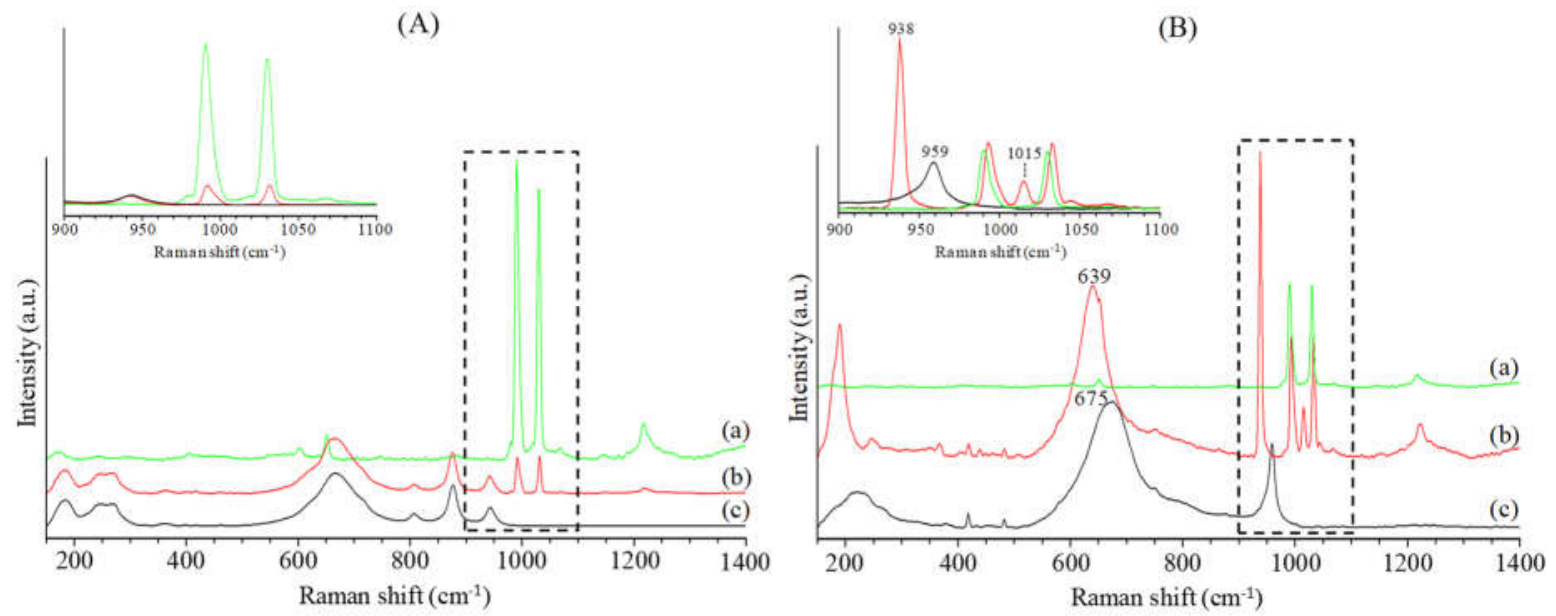

Figure 6. Raman spectra of (a) pyridine, (b) protonated sample + pyridine $\left(\mathrm{R}_{\mathrm{m}}>16\right)$, (c) protonated sample. Inset shows the enlargement in the $900-1100 \mathrm{~cm}^{-1}$ region. Protonated sample: (A) $\mathrm{H}_{2} \mathrm{~W}_{2} \mathrm{O}_{7}$, (B) $\mathrm{H}_{2} \mathrm{WO}_{4}$.For comparison, spectra of the solid were normalized: (A) to the band at $805 \mathrm{~cm}^{-1}$ for $\mathrm{H}_{2} \mathrm{~W}_{2} \mathrm{O}_{7}$ or (B) to the band at $417 \mathrm{~cm}^{-1}$ (Raman probe) for $\mathrm{H}_{2} \mathrm{WO}_{4}$.

By contrast with $\mathrm{H}_{2} \mathrm{~W}_{2} \mathrm{O}_{7}$, intercalation into $\mathrm{H}_{2} \mathrm{WO}_{4}$ revealed several changes (Figure 6B). Peaks at 959 and 675 were strongly red shifted to 938 and $639 \mathrm{~cm}^{-1}$ respectively, with a simultaneous relative increase in the intensity of the peak at $938 \mathrm{~cm}^{-1}$ compared to the intensity of the peak at $639 \mathrm{~cm}^{-1}$. The bands of pyridine also shifted from 990 and 1031 to 993 and $1035 \mathrm{~cm}^{-1}$ respectively in addition to the presence of a new peak which developed at $1015 \mathrm{~cm}^{-1}$ between the latter two. These various changes indicate the interaction between the pyridine and the host lattice, notably the (W-O) bonds. 
(A)

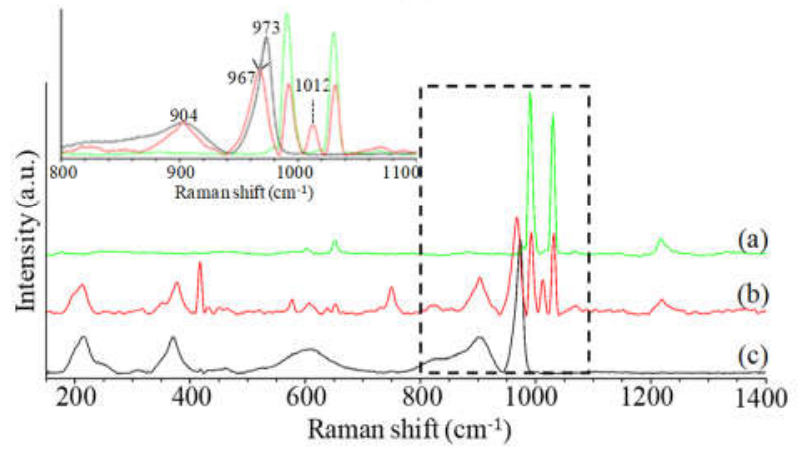

(B)

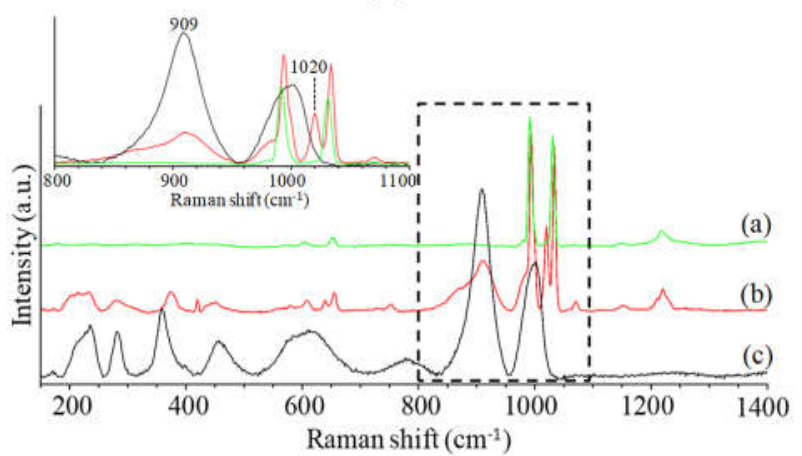

Figure 7. Raman spectra of (a) pyridine, (b) protonated sample + pyridine $\left(\mathrm{R}_{\mathrm{m}}>6\right)$, (c) protonated sample. Inset shows the enlargement in the $800-1100 \mathrm{~cm}^{-1}$ region. Protonated sample: (A) $\mathrm{HNbMoO}_{6}$, (B) $\mathrm{HNbWO}_{6}$.

In presence of $\mathrm{HNbMoO}_{6}$, in addition to the peaks due to unperturbed pyridine which were not shifted, new peaks developed at 1001 and $1012 \mathrm{~cm}^{-1}$ (Figure 7). In the case of $\mathrm{HNbWO}_{6}$, these peaks were at ca. 1000 and $1020 \mathrm{~cm}^{-1}$. Meanwhile, the vibration band of $\mathrm{Mo}=\mathrm{O}$ only shifted from 973 to $967 \mathrm{~cm}^{-1}$ and that of $\mathrm{W}=\mathrm{O}$ from 991 to $981 \mathrm{~cm}^{-1}$ respectively. On the contrary, it is noteworthy that no such shift was observed for the $v(\mathrm{Nb}=\mathrm{O})$ vibration which remained at ca. $900 \mathrm{~cm}^{-1}$.

H-bonded pyridine is expected to show peaks around $996-1005 \mathrm{~cm}^{-1}$, as attributed by Ferwerda et al. [58] while Brønsted and Lewis acid sites may lead to bands in the range 10061015 and 1016-1028 $\mathrm{cm}^{-1}$, respectively. For instance, bands at ca. $1014 \mathrm{~cm}^{-1}$ were observed for HY zeolite [58] and sulfated zirconia [59]. Nevertheless, these boundaries are indicative and also depend on other aspects like the pyridine coverage on the surface. In view of the similar intrinsic characteristics of $\mathrm{HNbMoO}_{6}$ and $\mathrm{HNbWO}_{6}$, they are not expected to show a different type of acidity. Both are expected to show principally Brønsted acidity $[13,24]$. This could indicate a higher Brønsted acidity for $\mathrm{HNbWO}_{6}$ compared to $\mathrm{HNbMoO}_{6}$ as the Raman shift of the $v_{1}$ band normally increases with the acid strength [58]. Conversely, $\mathrm{H}_{2} \mathrm{WO}_{4}$, close to $\mathrm{WO}_{3}$, is expected to show a more pronounced Lewis acid character [30,60,61], while its band is found in the same range, at $1015 \mathrm{~cm}^{-1}$.

To determine whether pyridine interacted with available Brønsted or Lewis acidic sites the solids, intercalated with pyridine, dried and pelletized by mixing with $95 \% \mathrm{KBr}$, were characterized by Fourier transform infrared spectroscopy (Figure 8). Results differed largely between $\mathrm{H}_{2} \mathrm{WO}_{4}$ and the mixed oxides. 
For $\mathrm{H}_{2} \mathrm{WO}_{4}$, a strong IR band is observed at $1444 \mathrm{~cm}^{-1}$ with weaker bands at 1605 and $1572 \mathrm{~cm}^{-1}$ attributed to pyridine adsorbed on Lewis acid sites [62]. By contrast, there is no indication of Brønsted acid sites as bands at 1535 and $1635 \mathrm{~cm}^{-1}$ attributed to pyridinium ions [62] were hardly visible. For $\mathrm{HNbMoO}_{6}$ and $\mathrm{HNbWO}_{6}$, pyridine peaks were found at 1634 , 1608,1534 and $1486 \mathrm{~cm}^{-1}$, that are attributed to the ring-stretching mode of pyridinium ions interacting with Brønsted acid sites [62]. The band at ca. $1450 \mathrm{~cm}^{-1}$ due to pyridine interacting with Lewis acid sites was not observed in both cases.

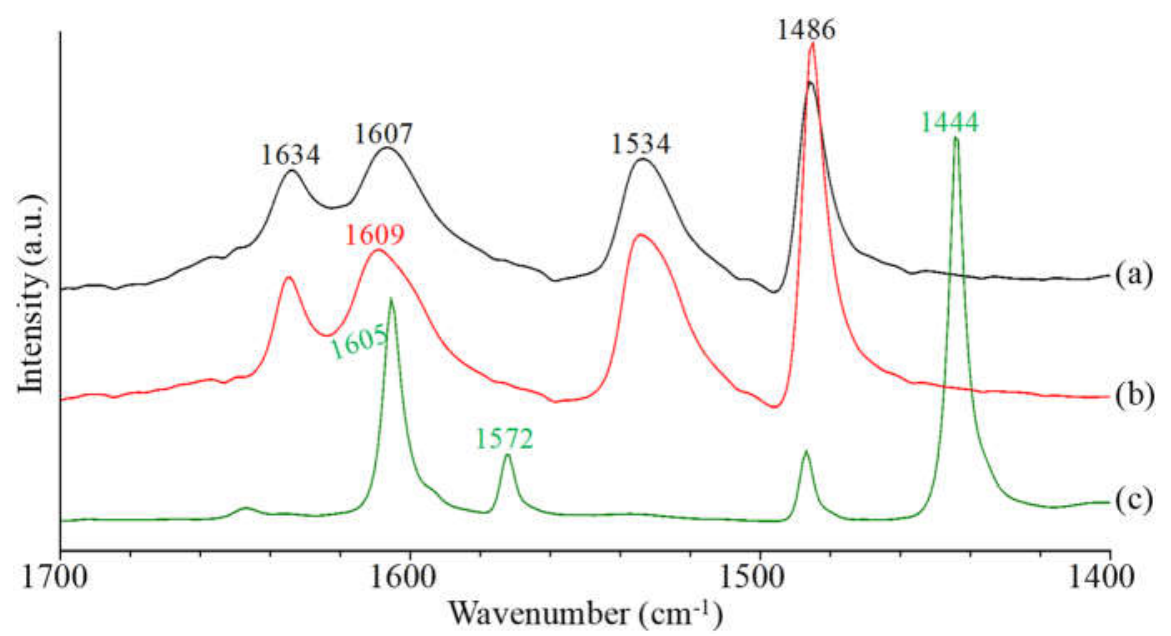

Figure 8. IR spectra of (a) $\mathrm{HNbMoO}_{6}+$ pyridine, (b) $\mathrm{HNbWO}_{6}+$ pyridine and (c) $\mathrm{H}_{2} \mathrm{WO}_{4}+$ pyridine.

These results are consistent with the expansions of the interlayers discussed above: $\mathrm{H}_{2} \mathrm{WO}_{4}$ shows a nearly perpendicular orientation of pyridine which is more likely if the Natom of pyridine interacts with the surface Lewis acid sites (Supplementary Information, Figure S13). Meanwhile, after protonation has occurred, pyridine is more conveniently accommodated parallel to the surface of the Brønsted solid acids, $\mathrm{HNbMoO}_{6}$ and $\mathrm{HNbWO}_{6}$.

Acidities of the three solids are thus consistent with what could be forecasted (Lewis acidity for $\mathrm{H}_{2} \mathrm{WO}_{4}$ and Brønsted acidity for $\mathrm{HNbMoO}_{6}$ and $\mathrm{HNbWO}_{6}$ ). Nevertheless, the position of the $v_{1}$ band observed in Raman spectroscopy is not sufficient in itself to discriminate between the two types of acidities. However, the band shifts of the solid after pyridine intercalation can also be taken as indicative of the type of acidity involved. While the Brønsted acidic solids gave rise to only minor shifts of the $v(\mathrm{~W}(\mathrm{Mo})=\mathrm{O})$ bands (less than $10 \mathrm{~cm}^{-1}$ ), the interaction with Lewis sites gave rise to band shifts of ca. $30 \mathrm{~cm}^{-1}$, both for the bands at 960 and $675 \mathrm{~cm}^{-1}$. This is likely due to the direct interaction of pyridine with the tungstate Lewis sites, while the interaction of pyridine with protonic sites only indirectly perturbs the surface sites. In the case of the mixed oxides, $\mathrm{HNbMoO}_{6}$ and $\mathrm{HNbWO}_{6}$, the 
slight shift of the bands attributed to $\mathrm{W}(\mathrm{Mo}) \mathrm{O}$ bonds and the absence of shift for the band assigned to $\mathrm{NbO}$ vibrations indicates that the stronger Brønsted acidity able to protonate pyridine is thus more likely associated with the $\mathrm{W}(\mathrm{Mo}) \mathrm{O}$ environment. By contrast, protons in the vicinity of $\mathrm{Nb}=\mathrm{O}$ bonds are likely weaker as the $\mathrm{NbO}$ vibrations are not modified upon pyridine intercalation. They can only interact with stronger bases like n-alkylamines, inducing as noted in the previous section, the shift of the $\mathrm{NbO}$ vibration around $900 \mathrm{~cm}^{-1}$.

Therefore, this methodology allows the direct titration of the acidic sites in the interlayer. Acidic sites monitored by Raman spectroscopy are indeed related to the probe intercalation, as confirmed also by the PXRD measurements carried out after sample separation from the liquid. In addition, it may also be used to correlate the acidic sites with the inorganic layers.

\section{Conclusion}

The intercalation process of organic bases was studied for several transition metal oxides layered materials, $\mathrm{H}_{2} \mathrm{~W}_{2} \mathrm{O}_{7}, \mathrm{H}_{2} \mathrm{WO}_{4}, \mathrm{HNbWO}_{6}$ and $\mathrm{HNbMoO}_{6}$. Intercalation of the $\mathrm{N}$ containing compounds was also confirmed by PXRD. All solids were able to intercalate butylamine and octylamine, showing that these amines are unable to discriminate between these acidic layered materials. However, pyridine could only intercalate into $\mathrm{H}_{2} \mathrm{WO}_{4}$, $\mathrm{HNbMoO}_{6}$ and $\mathrm{HNbWO}_{6}$.

Beside PXRD results, Raman spectroscopy of the layered materials in the liquid phase granted new molecular insights, first on the solids to follow the protonation process of the precursors and second, in the liquid phase in presence of the intercalating molecules. In these conditions, the bands of the solids and of the molecules can be simultaneously monitored. Nalkylamines and pyridine show evidence of protonation after contacting the solid which also confirms the intercalation observed by PXRD and the accessibility of the acidic sites for $\mathrm{HNbMoO}_{6}$ and $\mathrm{HNbWO}_{6}$. With n-alkylamines, both $\mathrm{NbO}$ and $\mathrm{W}(\mathrm{Mo}) \mathrm{O}$ bonds are affected similarly which indicates that the two metals in these mixed solids are associated with the relatively weak acidic sites. Similarly, $\mathrm{H}_{2} \mathrm{~W}_{2} \mathrm{O}_{7}$ and $\mathrm{H}_{2} \mathrm{WO}_{4}$ can host n-alkylamines which also affects the WO sites. Nevertheless, in presence of these rather strong bases, a reordering of the surface sites of $\mathrm{H}_{2} \mathrm{~W}_{2} \mathrm{O}_{7}$ is observed to finally resemble $\mathrm{H}_{2} \mathrm{WO}_{4}$. By contrast, the mixed oxides $\mathrm{HNbMoO}_{6}$ and $\mathrm{HNbWO}_{6}$ appeared much more stable.

Pyridine is similarly affected by the interaction with layered solids, but its weaker basicity allows distinguishing more finely between the layered materials. First, it is not at all 
perturbed by $\mathrm{H}_{2} \mathrm{~W}_{2} \mathrm{O}_{7}$, which is consistent with the absence of intercalation. Conversely, the Lewis acid sites of $\mathrm{H}_{2} \mathrm{WO}_{4}$ interact with pyridine inducing the development of a new band and large perturbations of the WO vibrations. For the $\mathrm{HNbMoO}_{6}$ and $\mathrm{HNbWO}_{6}$ solids, a band related to Brønsted acid sites develops, in parallel with the sole perturbation of $\mathrm{W}(\mathrm{Mo}) \mathrm{O}$ bonds while $\mathrm{NbO}$ sites appear unaffected. This defines more clearly the location of the acidic sites on the interlayer surface. Besides, $\mathrm{HNbMoO}_{6}$ and $\mathrm{HNbWO}_{6}$ can also be distinguished by the larger displacement of the new pyridine band for $\mathrm{HNbWO}_{6}$ indicating a probable higher strength.

Therefore, Raman monitoring in the liquid phase not only enables to follow the intercalation process in layered materials, improving the molecular understanding of the interlayer surface, but it also allows to efficiently characterize the acidity and discriminate between different acidic strengths. This comprehensive approach also allows the continuous monitoring of the intercalation. It is thus more informative than the methodologies usually reported where studies of intercalation and acidity are usually performed separately and after the final incorporation of the intercalating molecule. This will assist the selection of layered materials but more generally of catalysts for conversions in the liquid phase. This methodology can also be used to follow directly the intercalation of the reactants themselves for liquid phase conversions. Finally, in view of their stability and Brønsted acidity, mixed layered oxides such as $\mathrm{HNbMoO}_{6}$ and $\mathrm{HNbWO}_{6}$ appear to be interesting candidates for such conversions.

\section{Author information}

Corresponding author: e-mail: guillaume.clet@ensicaen.fr

\section{Conflicts of interest}

There are no conflicts to declare.

\section{Acknowledgments}

The authors acknowledge the financial support from the French Ministry of Education and Research and from the French Agence Nationale de la Recherche and LabEx EMC3 through the project OXYLAC (Grant No.ANR-10-LABX-09-01). The authors thank Sylvie Collin (CRISMAT) for her help in the samples preparation. 


\section{References:}

[1] R. Rinaldi, F. Schuth, Design of solid catalysts for the conversion of biomass, Energy Environ. Sci. 2 (2009) 610-626. https://doi.org/10.1039/b902668a.

[2] J.C. Serrano-Ruiz, R. Luque, A. Sepulveda-Escribano, Transformations of biomassderived platform molecules: from high added-value chemicals to fuelsvia aqueous-phase processing, Chem. Soc. Rev. 40 (2011) 5266-5281. https://doi.org/10.1039/c1cs15131b.

[3] P. Bhaumik, P.L. Dhepe, Solid acid catalyzed synthesis of furans from carbohydrates, Catal. Rev. 58 (2016) 36-112. https://doi.org/10.1080/01614940.2015.1099894.

[4] R.-J. van Putten, J.C. van der Waal, E. de Jong, C.B. Rasrendra, H.J. Heeres, J.G. de Vries, Hydroxymethylfurfural, A Versatile Platform Chemical Made from Renewable Resources, Chem. Rev. 113 (2013) 1499-1597. https://doi.org/10.1021/cr300182k.

[5] F. Guo, Z. Fang, C.C. Xu, R.L. Smith, Solid acid mediated hydrolysis of biomass for producing biofuels, Progress in Energy and Combustion Science. 38 (2012) 672-690. https://doi.org/10.1016/j.pecs.2012.04.001.

[6] Y.C. Sharma, B. Singh, J. Korstad, Advancements in solid acid catalysts for ecofriendly and economically viable synthesis of biodiesel, Biofuels, Bioproducts and Biorefining. 5 (2011) 69-92. https://doi.org/10.1002/bbb.253.

[7] T. Okuhara, Water-Tolerant Solid Acid Catalysts, Chem. Rev. 102 (2002) 3641-3666. https://doi.org/10.1021/cr0103569.

[8] M. Osada, T. Sasaki, Exfoliated oxide nanosheets: new solution to nanoelectronics, J. Mater. Chem. 19 (2009) 2503-2511. https://doi.org/10.1039/b820160a.

[9] Y. Ebina, T. Sasaki, M. Harada, M. Watanabe, Restacked Perovskite Nanosheets and Their Pt-Loaded Materials as Photocatalysts, Chem. Mater. 14 (2002) 4390-4395. https://doi.org/10.1021/cm020622e.

[10] C. Tagusagawa, A. Takagaki, S. Hayashi, K. Domen, Efficient Utilization of Nanospace of Layered Transition Metal Oxide HNbMoO6 as a Strong, Water-Tolerant Solid Acid Catalyst, J. Am. Chem. Soc. 130 (2008) 7230-7231. https://doi.org/10.1021/ja802478d.

[11] J. Zhong, Y. Guo, J. Chen, Protonated and layered transition metal oxides as solid acids for dehydration of biomass-based fructose into 5-hydroxymethylfurfural, Journal of Energy Chemistry. 26 (2017) 147-154. http://dx.doi.org/10.1016/j.jechem.2016.09.010.

[12] A.S. Dias, S. Lima, D. Carriazo, V. Rives, M. Pillinger, A.A. Valente, Exfoliated titanate, niobate and titanoniobate nanosheets as solid acid catalysts for the liquid-phase dehydration of d-xylose into furfural, J. Catal. 244 (2006) 230-237. http://dx.doi.org/10.1016/j.jcat.2006.09.010.

[13] A. Takagaki, C. Tagusagawa, S. Hayashi, M. Hara, K. Domen, Nanosheets as highly active solid acid catalysts for green chemical syntheses, Energy Environ. Sci. 3 (2010) 82-93. https://doi.org/10.1039/b918563a.

[14] A. Takagaki, R. Sasaki, C. Tagusagawa, K. Domen, Intercalation-induced Esterification over a Layered Transition Metal Oxide, Top. Catal. 52 (2009) 592-596. https://doi.org/10.1007/s11244-009-9194-4. 
[15] A. Takagaki, C. Tagusagawa, K. Domen, Glucose production from saccharides using layered transition metal oxide and exfoliated nanosheets as a water-tolerant solid acid catalyst, Chem. Commun. (2008) 5363-5365. https://doi.org/10.1039/b810346a.

[16] C. Tagusagawa, A. Takagaki, S. Hayashi, K. Domen, Evaluation of strong acid properties of layered $\mathrm{HNbMoO} 6$ and catalytic activity for Friedel-Crafts alkylation, Catalysis Today. 142 (2009) 267-271. https://doi.org/10.1016/j.cattod.2008.10.045.

[17] C. Tagusagawa, A. Takagaki, K. Takanabe, K. Ebitani, S. Hayashi, K. Domen, Layered and nanosheet tantalum molybdate as strong solid acid catalysts, Journal of Catalysis. 270 (2010) 206-212. https://doi.org/10.1016/j.jcat.2009.12.019.

[18] Q. Wu, Y. Yan, Q. Zhang, J. Lu, Z. Yang, Y. Zhang, Y. Tang, Catalytic Dehydration of Carbohydrates on In Situ Exfoliatable Layered Niobic Acid in an Aqueous System under Microwave Irradiation, ChemSusChem. $6 \quad$ (2013) 820-825. https://doi.org/10.1002/cssc.201300004.

[19] Y. Morita, S. Furusato, A. Takagaki, S. Hayashi, R. Kikuchi, S.T. Oyama, IntercalationControlled Cyclodehydration of Sorbitol in Water over Layered-Niobium-Molybdate Solid Acid, ChemSusChem. 7 (2014) 748-752. https://doi.org/10.1002/cssc.201300946.

[20] X.-Q. Xu, L. Zhao, X.-J. Guo, S.-F. Wang, T. Yu, S.-M. Liu, H.-H. Liu, L.-R. Zhang, B.-J. Li, Intercalation of layered HMMoO6 $(\mathrm{M}=\mathrm{Ta}, \mathrm{Nb})$ with oligomeric polyhydroxyacetato-Cr(III) species and propping up of HMMoO6 with chromium oxide as pillars, Polyhedron. 97 (2015) 208-214. http://dx.doi.org/10.1016/j.poly.2015.05.012.

[21] Y. Tsunoda, W. Sugimoto, Y. Sugahara, Intercalation Behavior of n-Alkylamines into a Protonated Form of a Layered Perovskite Derived from Aurivillius Phase Bi2SrTa2O9, Chem. Mater. 15 (2003) 632-635. https://doi.org/10.1021/cm0200893.

[22] N.S.P. Bhuvanesh, J. Gopalakrishnan, Synthesis of Rutile-Related Oxides, LiMMoO6 $(\mathrm{M}=\mathrm{Nb}, \mathrm{Ta})$, and Their Proton Derivatives. Intercalation Chemistry of Novel Broensted Acids, HMMoO6.H2O, Inorg. Chem. $34 \quad$ (1995) 3760-3764. https://doi.org/10.1021/ic00118a025.

[23] V. Bhat, J. Gopalakrishnan, HNbWO6 and HTaWO6: Novel layered oxides related to the rutile structure. Synthesis and investigation of ion-exchange and intercalation behaviour, Solid State Ionics. 26 (1988) 25-32. http://dx.doi.org/10.1016/01672738(88)90241-X.

[24] C. Tagusagawa, A. Takagaki, K. Takanabe, K. Ebitani, S. Hayashi, K. Domen, Effects of Transition-Metal Composition of Protonated, Layered Nonstoichiometric Oxides H1-xNb1-xMo1+xO6 on Heterogeneous Acid Catalysis, J. Phys. Chem. C. 113 (2009) 17421-17427. https://doi.org/10.1021/jp906628k.

[25] C. Tagusagawa, A. Takagaki, S. Hayashi, K. Domen, Characterization of HNbWO6 and HTaWO6 Metal Oxide Nanosheet Aggregates As Solid Acid Catalysts, J. Phys. Chem. C. 113 (2009) 7831-7837. https://doi.org/10.1021/jp900525a.

[26] J. He, Q.J. Li, Y. Tang, P. Yang, A. Li, R. Li, H.Z. Li, Characterization of HNbMoO6, HNbWO6 and HTiNbO5 as solid acids and their catalytic properties for esterification reaction, Appl. Catal. A. 443-444 (2012) 145-152. http://dx.doi.org/10.1016/j.apcata.2012.07.036. 
[27] G. Busca, Spectroscopic characterization of the acid properties of metal oxide catalysts, Catal. Today. 41 (1998) 191-206.

[28] G. Busca, The surface acidity of solid oxides and its characterization by IR spectroscopic methods. An attempt at systematization, Phys. Chem. Chem. Phys. 1 (1999) 723-736.

[29] J.A. Lercher, C. Gründling, G. Eder-Mirth, Infrared studies of the surface acidity of oxides and zeolites using adsorbed probe molecules, Catal. Today. 27 (1996) 353-376.

[30] G. Ramis, C. Cristiani, A.S. Elmi, P. Villa, G. Busca, Characterization of the surface properties of polycrystalune WO3, J. Molec. Catal. 61 (1990) 319-331. https://doi.org/10.1016/0304-5102(90)80006-5.

[31] J. Chauvin, K. Thomas, G. Clet, M. Houalla, Comparative Influence of Surface Tungstate Species and Bulk Amorphous WO3 Particles on the Acidity and Catalytic Activity of Tungsten Oxide Supported on Silica, Journal of Physical Chemistry C. 119 (2015) 12345-12355. https://doi.org/10.1021/acs.jpcc.5b01479.

[32] M.R. Waller, T.K. Townsend, J. Zhao, E.M. Sabio, R.L. Chamousis, N.D. Browning, F.E. Osterloh, Single-Crystal Tungsten Oxide Nanosheets: Photochemical Water Oxidation in the Quantum Confinement Regime, Chem. Mater. 24 (2012) 698-704. https://doi.org/10.1021/cm203293j.

[33] R.E. Schaak, T.E. Mallouk, Exfoliation of layered rutile and perovskite tungstates, Chem. Commun. (2002) 706-707. https://doi.org/10.1039/b110220f.

[34] V.D. Nithya, R. Kalai Selvan, D. Kalpana, L. Vasylechko, C. Sanjeeviraja, Synthesis of Bi2WO6 nanoparticles and its electrochemical properties in different electrolytes for pseudocapacitor electrodes, Electrochimica Acta. $109 \quad$ (2013) 720-731. https://doi.org/10.1016/j.electacta.2013.07.138.

[35] T. Saison, P. Gras, N. Chemin, C. Chanéac, O. Durupthy, V. Brezová, C. ColbeauJustin, J.-P. Jolivet, New Insights into Bi2WO6 Properties as a Visible-Light Photocatalyst, J. Phys. Chem. C. $117 \quad$ (2013) 22656-22666. https://doi.org/10.1021/jp4048192.

[36] M. Kudo, H. Ohkawa, W. Sugimoto, N. Kumada, Z. Liu, O. Terasaki, Y. Sugahara, A Layered Tungstic Acid H2W2O7·nH2O with a Double-Octahedral Sheet Structure: Conversion Process from an Aurivillius Phase Bi2W2O9 and Structural Characterization, Inorg. Chem. $42 \quad$ (2003) 4479-4484. https://doi.org/10.1021/ic0206746.

[37] P. Shen, H.T. Zhang, H. Liu, J.Y. Xin, L.F. Fei, X.G. Luo, R.Z. Ma, S.J. Zhang, CoreshellFe3O4@SiO2@HNbMoO6 nanocomposites: new magnetically recyclable solid acid for heterogeneous catalysis, J. Mater. Chem. A. 3 (2015) 3456-3464. https://doi.org/10.1039/C4TA05479B.

[38] M. Maczka, L. Macalik, J. Hanuza, Raman and IR spectra of the cation-deficient Aurivillius layered crystal Bi2W2O9, J. Raman Spectrosc. 40 (2009) 2099-2103. https://doi.org/10.1002/jrs.2378.

[39] H.C. Gupta, Archana, V. Luthra, A lattice dynamical investigation for the Raman and the infrared frequencies of Bi2W2O9, Physica B: Condensed Matter. 407 (2012) 477484. https://doi.org/10.1016/j.physb.2011.11.019. 
[40] T. Barré, L. Arurault, F.X. Sauvage, Chemical behavior of tungstate solutions. Part 1. A spectroscopic survey of the species involved, Spectroc. Acta A. 61 (2005) 551-557.

[41] V.I. Tsaryuk, V.F. Zolin, Vibration and vibronic spectra of lanthanide compounds with different types of coordination polyhedra of tungsten and molybdenum, Spectroc. Acta A. (2001) 355-359.

[42] A.Z. Sadek, H. Zheng, M. Breedon, V. Bansal, S.K. Bhargava, K. Latham, J. Zhu, L. $\mathrm{Yu}$, Z. Hu, P.G. Spizzirri, W. Wlodarski, K. Kalantar-zadeh, High-Temperature Anodized WO3 Nanoplatelet Films for Photosensitive Devices, Langmuir. 25 (2009) 9545-9551. https://doi.org/10.1021/la901944x.

[43] C. Ng, C. Ye, Y.H. Ng, R. Amal, Flower-Shaped Tungsten Oxide with Inorganic Fullerene-like Structure: Synthesis and Characterization, Crystal Growth \& Design. 10 (2010) 3794-3801. https://doi.org/10.1021/cg100625m.

[44] M.F. Daniel, B. Desbat, J.C. Lassegues, B. Gerand, M. Figlarz, Infrared and Raman Study of $\mathrm{WO}_{3}$ Tungsten Trioxides and $\mathrm{WO}_{3}, \mathrm{xH}_{2} \mathrm{O}$ Tungsten Trioxide Hydrates, J. Solid State Chem. 67 (1987) 235-247.

[45] L.-F. Hu, Y. Tang, J. He, K. Chen, W. Lv, Regioselective toluene nitration catalyzed with layered HNbMoO6, Russian Journal of Physical Chemistry A. 91 (2017) 511-516. https://doi.org/10.1134/S0036024417030177.

[46] Li-Fang $\mathrm{Hu}$, Rui Li, Jie He, Liang-guo Da, Wei Lv, Jin-song Hu, Structure and photocatalytic performance of layered HNbWO6 nanosheet aggregation, Journal of Nanophotonics. 9 (2015) 1-8.

[47] B. Ingham, S.V. Chong, J.L. Tallon, Layered tungsten oxide-based organic-inorganic hybrid materials: an infrared and Raman study, J. Phys. Chem. B. 109 (2005) 49364940.

[48] M. Maczka, J. Hanuza, W. Paraguassu, A. Gomes Souza Filho, P. Tarso Cavalcante Freire, J. Mendes Filho, Phonons in ferroelectric Bi2WO6: Raman and infrared spectra and lattice dynamics, Appl. Phys. Lett. $92 \quad$ (2008) 112911. https://doi.org/10.1063/1.2896312.

[49] D. Chen, Y. Sugahara, Tungstate-Based Inorganic-Organic Hybrid Nanobelts/Nanotubes with Lamellar Mesostructures: Synthesis, Characterization, and Formation Mechanism, Chem. Mater. $19 \quad$ (2007) 1808-1815. https://doi.org/10.1021/cm062039u.

[50] D. Chen, T. Li, L. Yin, X. Hou, X. Yu, Y. Zhang, B. Fan, H. Wang, X. Li, R. Zhang, T. Hou, H. Lu, H. Xu, J. Sun, L. Gao, A comparative study on reactions of n-alkylamines with tungstic acids with various W-O octahedral layers: Novel evidence for the "dissolution-reorganization" mechanism, Materials Chemistry and Physics. 125 (2011) 838-845. https://doi.org/10.1016/j.matchemphys.2010.09.039.

[51] M. Boulova, G. Lucazeau, Crystallite Nanosize Effect on the Structural Transitions of WO3 Studied by Raman Spectroscopy, Journal of Solid State Chemistry. 167 (2002) 425-434.

[52] J. Hanuza, M. Mczka, J.H. van der Maas, Vibrational Properties of Double Tungstates of the MIMIII(WO4)2 Family $(\mathrm{MI}=\mathrm{Li}, \mathrm{Na}, \mathrm{K}$; MIII $=\mathrm{Bi}, \mathrm{Cr})$, Journal of Solid State Chemistry. 117 (1995) 177-188. https://doi.org/10.1006/jssc.1995.1261. 
[53] F.D. Hardcastle, I.E. Wachs, Determination of the molecular structure of tungstates by Raman spectroscopy, J. Raman Spectrosc. 26 (1995) 397-405.

[54] S. Shoval, S. Yariv, The Interaction Between Roundup (Glyphosate) and Montmorillonite. Part II. Ion Exchange and Sorption Of iso-Propylammonium by Montmorillonite, Clays and Clay Minerals. 27 (1979) 29-38. https://doi.org/10.1346/CCMN.1979.0270104.

[55] A.L. García-Ponce, L. Moreno-Real, A.J. López, Intercalation of n-alkylamines into mixed niobyl-vanadyl phosphate, Journal of Solid State Chemistry. 87 (1990) 20-28. https://doi.org/10.1016/0022-4596(90)90060-B.

[56] J.J.C. Teixeira-Dias, L.A.E.B. de Carvalho, A.M.A. da Costa, I.M.S. Lampreia, E.F.G. Barbosa, Conformational studies by Raman spectroscopy and statistical analysis of gauche interactions in n-butylamine, Spectrochimica Acta Part A: Molecular Spectroscopy. 42 (1986) 589-597. https://doi.org/10.1016/0584-8539(86)80139-8.

[57] T. Sasaki, F. Izumi, M. Watanabe, Intercalation of Pyridine in Layered Titanates, Chem. Mater. 8 (1996) 777-782. https://doi.org/10.1021/cm950463h.

[58] R. Ferwerda, J.H. van der Maas, P.J. Hendra, Fourier transform Raman spectroscopy of pyridine adsorbed on faujasites, Vibrational Spectroscopy. 7 (1994) 37-47. https://doi.org/10.1016/0924-2031(94)85039-9.

[59] M.I. Zaki, A.A.M. Ali, A surface study of zirconia-based solid acids by Laser Raman spectroscopy of adsorbed pyridine, Colloids and Surfaces A. 119 (1996) 39-50.

[60] S.M. Kanan, J.K. Cox, G. Bernhardt, C.P. Tripp, Identification of surface sites on monoclinic WO3 powders by Infrared Spectroscopy, Langmuir. 18 (2002) 1707-1712.

[61] F. Mai, K. Cui, Z. Wen, K. Wu, F. Yan, M. Chen, H. Chen, Y. Li, Highly selective conversion of guaiacol to tert-butylphenols in supercritical ethanol over a H2WO4 catalyst, RSC Adv. 9 (2019) 2764-2771. https://doi.org/10.1039/C8RA07962E.

[62] T. Barzetti, E. Selli, D. Moscotti, L. Forni, Pyridine and ammonia as probes for FTIR analysis of solid acid catalysts, J. Chem. Soc., Faraday Trans. 92 (1996) 1401-1407. https://doi.org/10.1039/FT9969201401. 